\title{
Preliminary Investigation of Small Scale Superconducting Magnetic Energy Storage (SMES) Systems
}

by

J. Schwartz

E.E. Burkhardt

William R. Taylor

Most Army installations purchase electricity from local utilities and pay an additional charge for peak demand. If the peak demand can be reduced, installations can realize significant cost savings.

This research investigated the technical and economic issues associated with constructing a small scale superconducting magnetic energy storage (SMES) system for reducing peak demand at Army installations. Analyses included magnetic design parameters, and costs of materials currently available and those being developed.

Although advanced materials could reduce costs by as much as 45 percent, current SMES technology is still too costly for use at Army installations. Technological advances and future wide-spread use of SMES systems may reduce costs to the point where this alternative would be practical.

\section{For Reference}

Not to be taken from this room 
The contents of this report are not to be used for advertising, publication, or promotional purposes. Citation of trade names does not constitute an official endorsement or approval of the use of such commercial products. The findings of this report are not to be construed as an official Department of the Army position, unless so designated by other authorized documents.

DESTROY THIS REPORT WHEN IT IS NO LONGER NEEDED

DO NOT RETURN IT TO THE ORIGINATOR 


\section{USER EVALUATION OF REPORT}

\section{REFERENCE: USACERL Technical Report 96/41, Preliminary Investigation of Small Scale Supercon- ducting Magnetic Energy Storage (SMES) Systems}

Please take a few minutes to answer the questions below, tear out this sheet, and return it to USACERL. As user of this report, your customer comments will provide USACERL with information essential for improving future reports.

1. Does this report satisfy a need? (Comment on purpose, related project, or other area of interest for which report will be used.)

2. How, specifically, is the report being used? (Information source, design data or procedure, management procedure, source of ideas, etc.)

3. Has the information in this report led to any quantitative savings as far as manhours/contract dollars saved, operating costs avoided, efficiencies achieved, etc.? If so, please elaborate.

4. What is your evaluation of this report in the following areas?
a. Presentation:
b. Completeness:
c. Easy to Understand:
d. Easy to Implement:
e. Adequate Reference Material:
f. Relates to Area of Interest:

g. Did the report meet your expectations?

h. Does the report raise unanswered questions? 
i. General Comments. (Indicate what you think should be changed to make this report and future reports of this type more responsive to your needs, more usable, improve readability, etc.)

5. If you would like to be contacted by the personnel who prepared this report to raise specific questions or discuss the topic, please fill in the following information.

Name:

Telephone Number:

Organization Address:

6. Please mail the completed form to:

Department of the Army

CONSTRUCTION ENGINEERING RESEARCH LABORATORIES

ATTN: CECER-TR-I

P.O. Box 9005

Champaign, IL 61826-9005 


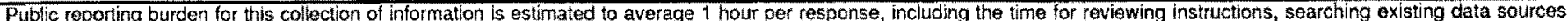

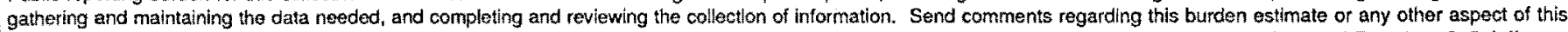

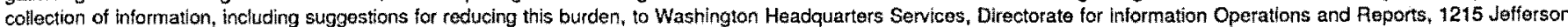
Davis Highway, Sulte 1204, Arlington, VA 22202-4302, and to the Oflice of Managoment and Budget, Paperwork Reduction Project (0704-0188), Washington, DC 20503.

\begin{tabular}{|c|c|c|c|}
\hline 1. AGENCY USE ONLY (Leave Blank) & $\begin{array}{l}\text { 2. REPORT DATE } \\
\text { January } 1996\end{array}$ & $\begin{array}{l}\text { 3. REPORT TYPE AN } \\
\text { Final }\end{array}$ & ES COVERED \\
\hline \multicolumn{3}{|c|}{$\begin{array}{l}\text { 4. TTLE AND SUBTTLE } \\
\text { Preliminary Investigation of Small Scale Superconducting Magnetic Energy Storage } \\
\text { (SMES) Systems }\end{array}$} & \multirow[t]{2}{*}{$\begin{array}{l}\text { 5. FUNDING NUMBERS } \\
\text { 4A162784 } \\
\text { AT45 } \\
\text { Work Unit EB-XP2 }\end{array}$} \\
\hline \multicolumn{3}{|c|}{$\begin{array}{l}\text { 6. AUTHOR(S) } \\
\text { J. Schwartz, E.E. Burkhardt, William R. Taylor }\end{array}$} & \\
\hline \multicolumn{3}{|c|}{$\begin{array}{l}\text { 7. PERFORMING ORGANIZATION NAME(S) AND ADDRESS(ES) } \\
\text { U.S. Army Construction Engineering Research Lab }\end{array}$} & $\begin{array}{l}\text { 8. PERFOORMING ORGANIZATIOI } \\
\text { REPORT NUMBER }\end{array}$ \\
\hline
\end{tabular}

P.O. Box 9005

Champaign, IL 61826-9005

TR $96 / 41$

9. SPONSORING / MONITORING AGENCY NAME(S) AND ADDRESS(ES)

U.S. Army Center for Public Works

ATTN: CECPW-E

7701 Telegraph Road

Alexandria, VA 22310-3862

11. SUPPLEMENTARY NOTES

Copies are available from the National Technical Information Service, 5285 Port Royal Road, Springfield, VA 22161.

12a. DISTRIBUTION / AVAILABILITY STATEMENT

126. DISTRIBUTION CODE

Approved for public release; distribution is unlimited.

13. ABSTRACT (Maximum 200 words)

Most Army installations purchase electricity from local utilities and pay an additional charge for peak demand. If the peak demand can be reduced, installations can realize significant cost savings.

This research investigated the technical and economic issues associated with constructing a small scale superconducting magnetic cnergy storage (SMES) system for reducing peak demand at Army installations. Analyses included magnetic design parameters, and costs of materials currently available and those being developed.

Although advanced materials could reduce costs by as much as 45 percent, current SMES technology is still too costly for use at Army installations. Technological advances and future wide-spread use of SMES systems may reduce costs to the point where this alternative would be practical.

\begin{tabular}{|c|c|c|c|}
\hline \multirow{2}{*}{\multicolumn{2}{|c|}{$\begin{array}{l}\text { 14. SUBJECT TERMS } \\
\text { Superconducting Magnetic Energy Storage (SMES) } \\
\text { energy storage } \\
\text { cost analysis }\end{array}$}} & \multirow[t]{2}{*}{ Army facilities } & $\begin{array}{l}\text { 15. NUMBER OF PAGES } \\
62\end{array}$ \\
\hline & & & 16. PRICE CODE \\
\hline $\begin{array}{l}\text { 17. SECURITY CLASSIFICATION } \\
\text { OF REPORT } \\
\text { Unclassified }\end{array}$ & $\begin{array}{l}\text { 18. SECURITY CLASSIFICATION } \\
\text { OF THIS PAGE } \\
\text { Unclassified }\end{array}$ & $\begin{array}{l}\text { 19. SECUAITY CLASSIFICATION } \\
\text { OF ABSTRACT } \\
\text { Unclassified }\end{array}$ & $\begin{array}{l}\text { 20. LIMITATION OF } \\
\text { ABSTRACT } \\
\text { SAR }\end{array}$ \\
\hline
\end{tabular}




\section{Foreword}

This study was conducted for U.S. Army Center for Public Works under Project 4A162784AT45, "Energy and Energy Conservation"; Work Unit EB-XP2, "Retrofit Technology for Electrical Energy Conservation." The technical monitor was S. Baidoo, CECPW-E.

The work was performed by the Department of Nuclear Engineering, University of Illinois, Champaign-Urbana, IL under contract to the Utilities Division (UL-U) of the Utilities and Industrial Operations Laboraroty (UL), U.S. Army Construction Engineering Research Laboratories (USACERL). J. Schwartz and E.E. Burkhardt are affiliated with the Department of Nuclear Engineering, University of Illinois. Martin J. Savoie is Acting Chief, CECER-UL-U, John T. Bandy is Operations Chief, and Gary W. Schanche is Chief, CECER-UL. The USACERL technical editor was Gloria J. Wienke, Technical Resources Center.

COL James T. Scott is Commander and Acting Director, USACERL, and Dr. Michael J. O'Connor is Technical Director. 


\section{Contents}

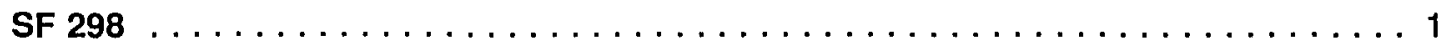

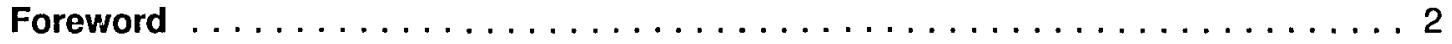

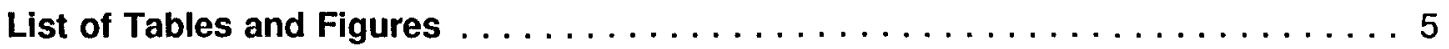

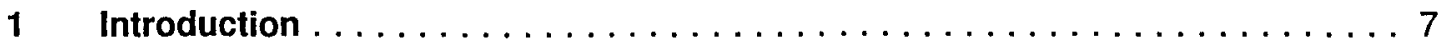

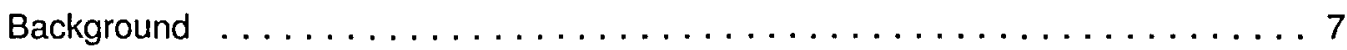

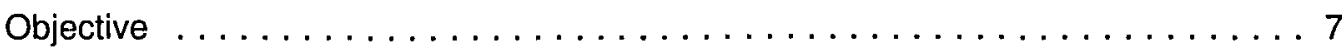

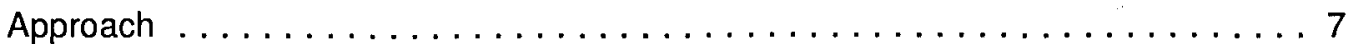

Mode of Technology Transfer $\ldots \ldots \ldots \ldots \ldots \ldots \ldots \ldots \ldots \ldots$

2 Storing Off Peak Energy $\ldots \ldots \ldots \ldots \ldots \ldots \ldots \ldots \ldots \ldots \ldots$

Pumped Hydroelectric Storage $\ldots \ldots \ldots \ldots \ldots \ldots \ldots \ldots \ldots$

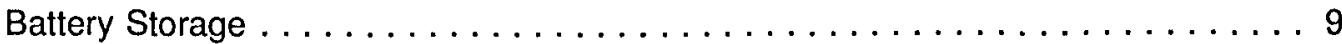

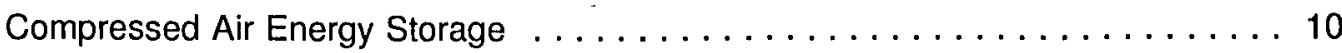

Superconducting Magnetic Energy Storage . . . . . . . . . . . . . 10

Superconducting Magnet Configurations $\ldots \ldots \ldots \ldots \ldots \ldots \ldots \ldots \ldots$

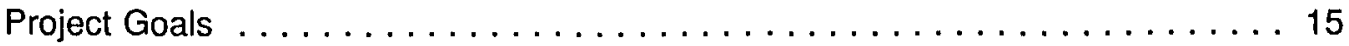

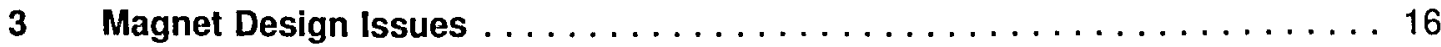

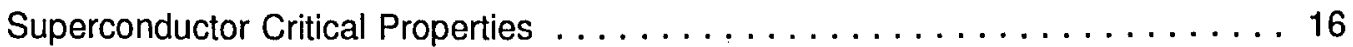

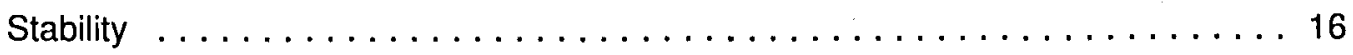

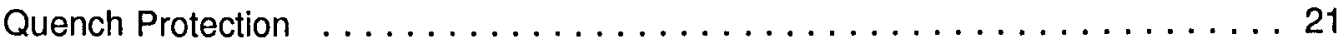

AC Losses . . . . . . . . . . . . . . . . . . . . . . . . . . . . . . 24

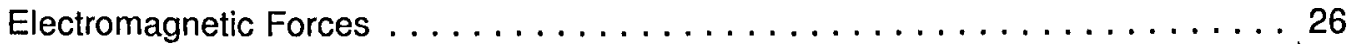

4 Superconducting Magnet Materials $\ldots \ldots \ldots \ldots \ldots \ldots \ldots \ldots \ldots \ldots$

Superconductors . . . . . . . . . . . . . . . . . . . . . . . . . . . . . . . 29

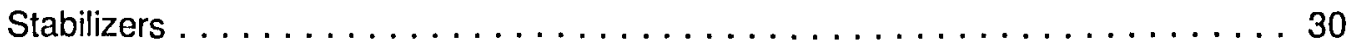

Structural Metals . . . . . . . . . . . . . . . . . . . . . . . . 31

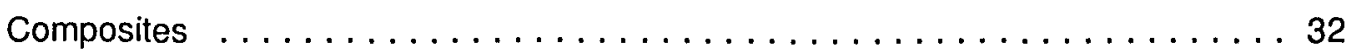

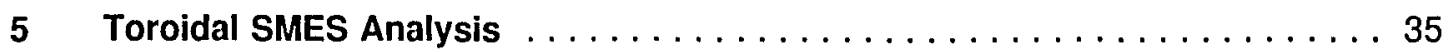

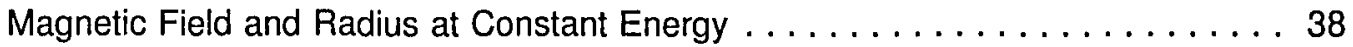

Cost Estimates . . . . . . . . . . . . . . . . . . . . . . . . . . . . 39

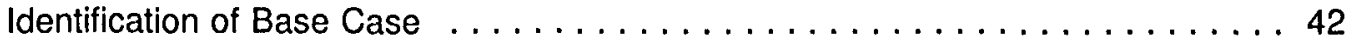

Future Technologies $\ldots \ldots \ldots \ldots \ldots \ldots \ldots \ldots \ldots \ldots \ldots$ 


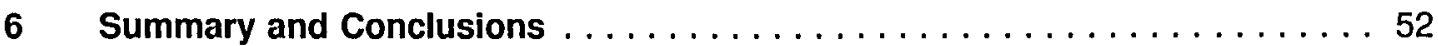

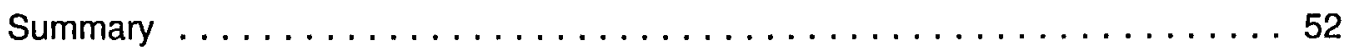

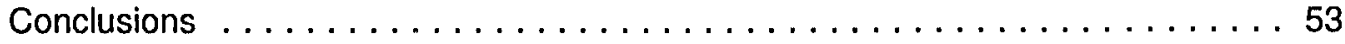

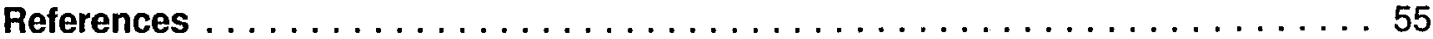

Distribution 


\section{List of Tables and Figures}

\section{Tables}

1

2

3

4

5

6

7

8

9

10

11

Figures
BPA coil parameters 11

Parameters of the 10,000 GWh toriod coil $\ldots \ldots \ldots \ldots \ldots \ldots 12$

Parameters of a $1000-M W h$ solenoid $\ldots \ldots \ldots \ldots \ldots \ldots \ldots \ldots$

Parameters for the ETM coil $\ldots \ldots \ldots \ldots \ldots \ldots \ldots \ldots \ldots$

Small toroid designs $\ldots \ldots \ldots \ldots \ldots \ldots \ldots \ldots \ldots \ldots$

Structural metals $\ldots \ldots \ldots \ldots \ldots \ldots \ldots \ldots \ldots \ldots \ldots \ldots$

Fibers for composites $\ldots \ldots \ldots \ldots \ldots \ldots \ldots \ldots \ldots$

Typical maximum fields for grades $\ldots \ldots \ldots \ldots \ldots \ldots \ldots$

Cost of materials $\ldots \ldots \ldots \ldots \ldots \ldots \ldots \ldots \ldots \ldots \ldots \ldots \ldots$

Base case parameters $\ldots \ldots \ldots \ldots \ldots \ldots \ldots \ldots \ldots$

Materials properties $\ldots \ldots \ldots \ldots \ldots \ldots \ldots \ldots \ldots \ldots$

A typical $J_{c}$ vs. $H_{c}$ plot of $\mathrm{NbTi}$ at $4.22 \mathrm{~K} \ldots \ldots \ldots \ldots \ldots$

Illustration of positive feedback system due to flux penetration or any other heat source $\ldots \ldots \ldots \ldots \ldots \ldots \ldots \ldots$

Loss factor $\Gamma(\beta)$ for hysteresis loss per cycle in a slab . . . . . . 25

Constant-tension Princeton-D geometry $\ldots \ldots \ldots \ldots \ldots \ldots$

Inner-leg cross section with fixed toroidal dimension $\ldots \ldots \ldots \ldots$ 
Radial build and $s_{\text {rad }}$ as a function of the conduit thermal expansion relative to the magnet case $\ldots \ldots \ldots \ldots \ldots \ldots \ldots \ldots \ldots$

Magnetic field $(B)$ vs. radius $\left(R_{0}\right)$ vs. $a \ldots \ldots \ldots \ldots \ldots \ldots$

Typical cost vs. $R_{0} \ldots \ldots \ldots \ldots \ldots \ldots \ldots \ldots \ldots \ldots \ldots \ldots$

Current density vs. field $\ldots \ldots \ldots \ldots \ldots \ldots \ldots \ldots \ldots$

Cost vs. current at $4.2 \mathrm{~K} \ldots \ldots \ldots \ldots \ldots \ldots \ldots \ldots$

Cost vs. current and temperature $\ldots \ldots \ldots \ldots \ldots \ldots \ldots \ldots$

Cost vs. number of coils in the toroidal array at $4.2 \mathrm{~K} \ldots \ldots \ldots 6$

Cost vs. number of coils in the toroidal array at $30 \mathrm{~K} \ldots \ldots \ldots 4$ 


\section{Introduction}

\section{Background}

Most Army installations purchase electricity from local utility companies rather than generate their own electricity. The rate structure for electrical costs includes a charge for peak demand. Peak demand is the average electrical load in a short period of time (typically, 15 or 30 minutes) during the customer's period of highest electrical use. This peak demand charge is usually a significant portion of installation electrical costs. If the peak electrical demand at Army installations can be reduced, significant electricity cost savings can be realized.

One method for reducing peak demand is by storing electrical energy that can be used in place of utility system power during peak demand periods. One method for storing off-peak electricity for on-peak use is superconducting magnetic energy storage (SMES). Although SMES technology would be most appropriate for use with utility transmission and distribution, a small scale system may help reduce peak electrical demand at installations.

\section{Objective}

The objective of this study was to investigate the technical and economic issues associated with constructing a scaled-down SMES sized for peak demand reductions on an Army installation.

\section{Approach}

To meet the research objective, researchers assessed SMES magnet design issues, evaluated superconducting magnet materials, and analyzed a sample design. 


\section{Mode of Technology Transfer}

It is anticipated that the results of this study will form the basis for further research into the use of SMES technology to reduce peak electrical demand at U.S. Army installations. 


\section{Storing Off Peak Energy}

\section{Pumped Hydroelectric Storage}

Pumped hydroelectric storage (or pumped hydro) uses electricity to pump water uphill to a reservoir. When electricity is needed, the water is released to a lower reservoir and used to drive turbines. Currently, pumped hydro accounts for about 3 percent of the total generating capacity of the United States, or 18,000 megawatts (MW); most other industrialized countries have as much as three to four times this amount (Moore 1986). The overall efficiency of this method is 65 to 70 percent (Masuda 1990). Pumped hydro is the only means of energy storage currently in widespread use. However, pumped hydro cannot be greatly expanded upon because it requires a large area to hold both the upper and lower reservoirs. Furthermore, most of the ideal sites are already being used. The total cost of this approach is about $\$ 1100$ per kilowatt (kW) (Boutacoff 1989).

\section{Battery Storage}

The oldest form of electrical energy storage is batteries. When batteries are used for energy storage, the off-peak power is used to charge the batteries, which can later deliver power as it is needed. Because this method is quiet and nonpolluting, it can be used in populated areas. Also, it has a short construction time, and since each battery stores only a small fraction of the energy, the problem of over building the needed storage capacity can be avoided. The total cost of batteries is $\$ 635 / \mathrm{kW}$; however, the problem with this method is that the batteries need to be replaced after approximately 15 years, and they need to be filled with fresh water periodically (Boutacoff 1989).

The Southern California Edison Company, with the help of the Electric Power Research Institute (EPRI, Palo Alto, CA) and the International Lead Zinc Research Organization (Research Triangle Park, NC) demonstrated a 2-year test program of battery storage at the Chino, CA, $10 \mathrm{MW} / 40 \mathrm{MWh}$ Battery Energy Storage Facility. This is the world's largest battery energy storage facility, containing 8,256 lead-acid batteries. The design uses eight parallel strings of 1,032 2-volt batteries in series for a total of 2000 volts direct current (dc). By the end of 1988, 46 tests had been completed. The results of the tests showed an overall plant efficiency of approximately 
70 to 72 percent. The demineralized water in the batteries required replacement after about 22 cycles (Rodriguez 1989; Rodriguez, Spindler, and Carr, undated).

\section{Compressed Air Energy Storage}

Compressed air energy storage (CAES) plants use off-peak electricity to compress air into an underground reservoir. The different types of reservoirs include caverns, salt or rock formations, aquifers, and depleted natural gas fields. This air can then be heated and used to drive generators by running it through expansion turbines. EPRI has sponsored several studies that have concluded that three-fourths of the United States has geology that could potentially be used for CAES and the required turbomachinery could be bought from numerous vendors at the present. The primary disadvantage to CAES is that the total cost is $\$ 425 / \mathrm{kW}$ (Boutacoff 1989).

\section{Superconducting Magnetic Energy Storage}

Superconducting magnetic energy storage plants store off-peak electricity by converting alternating current (ac) power to dc and feeding it into a solenoid- or toroidshaped magnet of superconducting wire. One of the advantages of SMES is its high efficiency. The efficiency for a superconducting magnet depends on the amount of stored energy. As the stored energy increases, the efficiency also increases. For a large system, one that can store $5000 \mathrm{MWh}$, the efficiency can be as high as 93.6 percent. The efficiency of a 100 MWh magnet is around 91.6 percent, and for a small unit (around $10 \mathrm{MWh}$ ) the efficiency is expected to be approximately 80 percent (Masuda 1990). The main loss in efficiency comes from powering the refrigeration system. For a large $5000 \mathrm{MWh}$ system, the coil would need to be about 1000 meters $(\mathrm{m})$ in diameter; however, for smaller systems, in the $10 \mathrm{kWh}$ range, which could be used for the stabilization of low frequency power oscillations, the coil may be as small as 3 to $4 \mathrm{~m}$ in diameter. One of the disadvantages of SMES may be its high construction cost. However, as the use of superconductors increases, the cost should decrease. Also, with the ongoing development of high temperature superconductors, liquid nitrogen ( $\mathrm{LN}$ ) may replace liquid helium $(\mathrm{LHe})$ as the refrigerant, leading to further cost reductions and increased efficiency (Boutacoff 1989).

The Bonneville Power Administration (BPA), Portland, OR, has used SMES for stabilizing low frequency power oscillations. Several other examples for proposed systems exist, ranging from small-scale approaches to systems designed to store as much as 36,000 GJ (gigajoules, or 10,000 MWh) of energy. 


\section{Bonneville Power Administration's SMES Coil}

The Bonneville Power Administration's superconducting, 30 megajoule (MJ) energy storage coil was installed in 1982 to demonstrate SMES as a frequency load stabilizer. SMES can be very effective at moderating system instabilities because it responds quickly to exchange electric power in approximately 10 milliseconds (ms.) The low frequency power oscillations found at BPA are common when the load and generation centers are separated by large distances. These oscillations occurred on the 2800-MW Pacific A.C. Intertie, which connects the southern California load to the hydroelectric power source of the Pacific Northwest (approximately 900 miles apart) (Hoffman, et al. 1981).

The coil was normally charged to $25 \mathrm{MJ}$, and, when necessary, either discharged or gained $5 \mathrm{MJ}$ of energy. The frequency of the oscillations that needed to be damped was $0.35 \mathrm{Hertz}(\mathrm{Hz})$. During normal operation the coil was unattended; an alarm would sound in the event of system malfunctions (Hoffman, et al. 1981).

Table 1 lists the main parameters of the magnet. The magnet is a solenoid consisting of 20 double-pancake coils. The peak magnetic field is $2.85 \mathrm{~T}$ and the peak current is $4900 \mathrm{~A}$. It is cooled by liquid helium at $4.5 \mathrm{Kelvin}(\mathrm{K})$. The conductor consists of one composite niobium-titanium/copper $(\mathrm{NbTi} / \mathrm{Cu})$ superconductor strand surrounded by six copper wires. Six of these subcables are then twisted around an insulated copper cable. Finally, 10 of these cables are twisted to form the 4.9-kiloamp (kA) conductor (Hoffman, et al. 1981). The cryostat is a toroidal-shaped fiber-reinforced plastic, openmouthed dewar. The cryogenic system includes a helium refrigerator, 17.25 mega Pascal (Mpa) compressors for gas recovery, a $1 \mathrm{MW}$ cooling tower, and a railroad tank car used for gas storage. The critical current of the wound magnet was never determined since the coil never quenched. The tests performed include testing the thermal loading of the converter, transformers, and current leads, dynamic testing by increasing and decreasing the current at different rates, and determining the behavior of the unit in the BPA transmission lines. Overall, the unit functioned as expected (Boenig et al. 1984).

\section{MWh Solenoid}

Many design studies of SMES systems for diurnal load leveling have been performed (Hoffman et al.; Loyd, Walsh, and Kimmey 1991; Shimizu et al. 1984a; Herring 1990). For large systems (equal to or greater than 1000 megawatt-hour [MWh]), it has

Table 1. BPA coll parameters.

\begin{tabular}{|l|l|}
\hline Parameter & Type/Units \\
\hline Coil type & Solenoid \\
\hline Stored energy & $8.4 \mathrm{kWh}$ \\
\hline Peak magnetic field & $2.85 \mathrm{~T}$ \\
\hline Peak current & $4900 \mathrm{~A}$ \\
\hline Coil configuration & Double-pancake \\
\hline Cpp; amt & Lhe $(4.5 \mathrm{~K})$ \\
\hline Diameter & $3.6 \mathrm{~m}$ \\
\hline
\end{tabular}


been proposed that the most cost-effective method of supporting very large magnetic pressure would be the use of bedrock for structural support. This is because the cost of building a metal structure may far exceed the cost of excavating a tunnel. The coil would be placed in a trench 5 to $7 \mathrm{~m}$ wide, 40 to $50 \mathrm{~m}$ high, with a diameter of about $100 \mathrm{~m}$. If a solenoid magnet is used, the entire magnet must be between 100 and $500 \mathrm{~m}$ underground due to the poor quality of rock near the surface and to limit the stray magnetic field. Typical coil parameters are shown in Table 2 (Boom et al. 1975).
Table 2. Parameters of the 10,000 GWh toriod coil.

\begin{tabular}{|l|l|}
\hline Parameter & Type/Units \\
\hline Coil type & Toroid \\
\hline Stored energy & $10,000 \mathrm{MWh}$ \\
\hline Peak magnetic field & $9.4 \mathrm{~T}$ \\
\hline Operating current & $100,000 \mathrm{~A}$ \\
\hline Cooland & Lhe $(4.2 \mathrm{~K})$ \\
\hline Diameter & $544 \mathrm{~m}$ \\
\hline Depth & $45 \mathrm{~m}$ \\
\hline
\end{tabular}

\section{The Engineering Test Model}

As an operating prototype of the 1000-MWh solenoid, an engineering test model (ETM) is being designed. The ETM will be designed to scale directly to the larger, 1000-MWh solenoid system. Two competing design studies exist; one is led by Bechtel the other by Ebasco (Hassenzahl 1989).

Proposed coil parameters can be seen in Table 3. The coil by the Bechtel team is 129 $\mathrm{m}$ in diameter, $7.5 \mathrm{~m}$ high, and will be constructed in a closed, steel lined, reinforced concrete trench (Hassenzahl 1989). This system will store 20.4 MWh in 112 turns of $200 \mathrm{kA}$ conductor. This current was selected to avoid arcing. As the voltage of the coil increases, the risk of arcing will also increase during normal operation, especially during a quench; however, as the current in the conductor increases, the risk remains constant. The only disadvantage of high conductor currents is the increased cost of refrigerating the vapor-cooled current leads (Hassenzahl 1989).

The liquid helium cryogen will be contained within the conductor. This choice was made due to the high risk associated with a separate helium containment vessel, which would require miles of helium-tight welds. The cost will be lower since the need for the helium vessel is eliminated and the helium inventory will be decreased (Hassenzahl 1989).

Since the critical current density $(J)$ is higher at lower temperatures and $1.8 \mathrm{~K}$ is obtainable, LHe-II coolant will be used to obtain an enhancement in $J_{c}$
Table 3. Parameters of a 1000-MWh solenoid.

\begin{tabular}{|l|l|}
\hline Parameter & Type/Units \\
\hline Coil type & Solenoid \\
\hline Stored energy & $1000 \mathrm{MWh}$ \\
\hline Peak magnetic field & $5 \mathrm{~T}$ \\
\hline Peak current & $157,000 \mathrm{~A}$ \\
\hline Coolant & LHell $(1.8 \mathrm{~K})$ \\
\hline Diameter & $100 \mathrm{~m}$ \\
\hline Depth & $100-500 \mathrm{~m}$ \\
\hline
\end{tabular}


relative to $4.2 \mathrm{~K}$. Two critical issues associated with $1.8 \mathrm{~K}$ operation are the cost of refrigeration and the increased likelihood of coolant leakage Loyd, Walsh, and Kimmey 1991).

A hollow-core cable-in-conduit-conductor (CICC) has been chosen over the monolithic configuration. By operating at around 80 percent of $J$ (over twice as much as a monolith design) the CICC may also be more cost effective. Further advantages of the CICC include simplified splicing (improved joints) and easily increased conductor current (by increasing the number of subcables per conductor and/or strands per subcable).

\section{$10 \mathrm{GWh}$ Toroid}

To avoid the great expense associated with complex subterranean engineering, toroid configurations are also proposed. A feasibility study for a $10 \mathrm{GWh}$ toroidal SMES system has been performed in Japan (Shimizu et al. 1984a). The coil is designed to optimize the weight, volume, and conductor length while making the coil easily accessible for fabrication and maintenance. Table 4 contains the main parameters for the coil. It is composed of 500 toroidal coils with a major radius of $272 \mathrm{~m}$ and an aspect ratio (major radius/minor radius) of about 20 . The only force that the rock mass needs to support is the centering force. The hoop forces are self-supported. The maximum field will be 9.4 Tesla (T). For fields above $8 \mathrm{~T}$, niobium-tin $(\mathrm{NbSn})$ with a copper matrix will be used. For fields below $8 \mathrm{~T}, \mathrm{NbTi}$ with a mixed matrix will be used to minimize ac losses. The coil will be cooled to $4.2 \mathrm{~K}$ using liquid helium (Shimizu 1984b).

\section{Small Toroids}

The Fusion Safety Program at the Idaho National Engineering Laboratory, Idaho Falls, ID conducted a study of small toroidal superconducting magnets ranging in size from 1 to $500 \mathrm{MJ}$ with fields ranging from 5 to $20 \mathrm{~T}$. The recent discovery of high temperature superconductors operating at liquid nitrogen temperatures has renewed the interest in small coils for mobile or spaceborne applications. Toroids are preferred for these purposes; the use of solenoids would not be reasonable because the external field would produce eddy currents in conducting items such as bridges, reinforcing rods or light poles, which will dissipate some of the stored energy. Another area of concern is the possibility of magnetic fields affecting members of the public

Table 4. Paraineters for the ETM coll.

\begin{tabular}{|l|l|}
\hline Parameters & Type/Units \\
\hline Coil type & Solenoid \\
\hline Stored energy & $20.4 \mathrm{MWh}$ \\
\hline Operating magnetic field & $4.13 \mathrm{~T}$ \\
\hline Peak current & $200,000 \mathrm{~A}$ \\
\hline Coil configuration & Double-pancake \\
\hline Coolant & Lhe-1I (1.8 K) \\
\hline Diameter & $129 \mathrm{~m}$ \\
\hline
\end{tabular}


wearing items such as pacemakers (Herring 1989). For applications in space, cosmic particles would be drawn toward the external field of a solenoid and the crew would receive higher doses of radiation (Herring 1990).

When used in mobile applications, small toroids can act as a buffer for the kinetic energy of a car, bus, or rail car. The kinetic energy could be stored in the coil when the brakes are applied and released when acceleration is needed. This could help minimize energy consumption. For example, a small automobile uses $30 \mathrm{~kW}$ to accelerate into traffic, but only requires $8.5 \mathrm{~kW}$ to maintain a constant speed of $55 \mathrm{mph}$. The results of eight separate coils are shown in Table 5 . $\mathrm{J}_{\mathrm{c}}$ was assumed to be $500 \mathrm{~A} / \mathrm{mm}^{2}$ in all cases, and the allowable stress in tension was assumed to be $250 \mathrm{MPa}$ for case $\mathrm{A}$, and $800 \mathrm{MPa}$ for the other seven cases.

The three 10-MJ units (cases A, C, and D) could be used with trucks and buses that frequently stop and start. This amount of energy is roughly the kinetic energy of a 20 tonne (t) vehicle travelling at $70 \mathrm{mph}$. By comparing units $\mathrm{A}$ and $\mathrm{C}$, the advantage of using the highest possible field is well demonstrated.

Case B illustrates a coil that could be used for small cars. A coil this size (1 MJ) could accelerate a 2-ton car to $70 \mathrm{mph}$. Not only is the unit compact (about the size of a spare tire), the liquid nitrogen would only require replacement every 5 days.

For larger vehicles, such as subways, case $\mathrm{E}$ would be suitable. This unit can store the energy of a $60 \mathrm{t}$ vehicle travelling at $70 \mathrm{mph}$ and could fit under the floor of the passenger compartment. For shipboard use, case F could be used. This system would be too large for train or truck shipment, but could be split into two halves and transported.

The last two systems are stationary units. Case $\mathrm{G}$ could be used by a utility for supplying $100 \mathrm{~T}_{\mathrm{c}}$ for 2.5 minutes. Case $\mathrm{H}$ was designed to launch a $5 \mathrm{t}$ projectile into orbit from the surface of the earth (Herring 1990).

Table 5. Small toroid designs.

\begin{tabular}{|c|c|c|c|c|c|c|c|c|}
\hline Case & $A$ & B & $\mathrm{c}$ & D & $\mathbf{E}$ & $\mathbf{F}$ & $\mathbf{G}$ & H \\
\hline$E_{s t}{ }^{*}(M J)$ & 10.0 & 1.05 & 10.8 & 10.6 & 31.3 & 1241 & 15,757 & 496,400 \\
\hline$B_{m}(T)$ & 5 & 15 & 15 & 10 & 20 & 15 & 10 & 15 \\
\hline$D(m)$ & 2.938 & 0.674 & 1.573 & 1.916 & 2.669 & 6.763 & 24.30 & 100.75 \\
\hline$m(\mathrm{~kg})$ & 2390 & 101 & 634 & 1661 & 2733 & 55,872 & $1.06 \mathrm{E} 6$ & 31.7E6 \\
\hline o (Mpa) & 250 & 800 & 800 & 800 & 800 & 800 & 800 & 800 \\
\hline
\end{tabular}




\section{Superconducting Magnet Configurations}

The two configurations typically used for the magnetic coil for SMES are solenoids and toroids. In general, solenoids are more commonly used in designs because they use about one-half the superconducting material of toroids. The type of structural support used depends on the size of the coil. For a large coil like the 1000-MWh solenoid, the ETM, or the 10-GWh toroid, bedrock is the most economical method of structural support; however, for smaller coils like the BPA $30 \mathrm{MJ}$ coil or the $10 \mathrm{MWh}$ coil in this study, the coil can be self-supporting.

Although the toroid generally requires more superconducting material and may have a higher materials cost than a solenoid, there are several factors that make a toroid favorable. For example, the toroid would have a smaller electromagnetic force so the rock mass would not need as much support and the problems of cracking and inhomogeneity in the rock would not be as great a concern. As a result of these lower forces, the coil could be placed in an open trench with a depth of $45 \mathrm{~m}$ compared to a tunnel $500 \mathrm{~m}$ underground for a solenoid. Other factors such as fabrication, repair, maintenance, and stray magnetic field make the toroid more desirable. With a toroid, the coil may be fabricated in a factory, whereas for a solenoid the coil must be fabricated in the tunnel. Furthermore, since the toroid can be in an open trench, maintenance is relatively simple. Finally, the stray magnetic field from a toroid is much lower than that from a solenoid. The radius for a 0.3 Gauss exposure (similar to terrestrial magnetism) for a solenoid is $2900 \mathrm{~m}$, but for a toroid it would be only 800 $\mathrm{m}$. Thus, the toroid is favorable near a populated area. Although the weight of the toroidal coil may be about 1.8 times heavier than the solenoid, the toroid has lower construction costs and more favorable siting criteria (Shimizu 1984a).

\section{Project Goals}

In this project, the technological and economic feasibility of a 10-MWh (36 GJ) SMES system will be analyzed. The technical limitations and physical constraints of designing a SMES 'system with available technology are assessed. The potential impact of future research in superconducting and structural materials is evaluated. For both of these cases, the economic feasibility of constructing a 10-MWh system will be considered. The key developmental requirements for eventual technological and economic success will be identified. 


\section{Magnet Design Issues}

The design of a superconducting magnet is limited by a variety of materials and electromagnetic constraints. In this section, these limits are reviewed and working parameter ranges are identified.

\section{Superconductor Critical Properties}

Several properties must be considered when choosing a superconductor. The two most important intrinsic properties are the critical temperature, $T_{c}$, and the upper critical magnetic field, $H_{c}$. If the temperature rises above $T_{c}$ or the field exceeds $H_{c}$ the superconductor will "go normal" and have a very large resistivity. The critical current density, $J_{c}$ magnetic flux density;temperature $(B ; T)$, on the other hand depends on lattice defects that are affected by the process in which the material is produced. A rule-of-thumb minimum for a superconducting material to produce a magnetic field is $\mathrm{J}_{\mathbf{c}}(\mathrm{B} ; \mathrm{T}) \sim 100 \mathrm{~A} / \mathrm{mm}^{2}$. (Superconducting materials options are reviewed in Chapter 4.) Figure 1 shows a typical $J_{c}-H_{c}-T_{c}$ plot for a superconducting material. $A_{s} H_{c}$ and $\mathrm{T}_{\mathrm{c}}$ are actually zero current values, the practical maximum field and temperature is the $\mathrm{H}-\mathrm{T}$ curve for the required current density.

\section{Stability}

Superconductors have a zero resistance and can therefore maintain a constant current virtually indefinitely. As can be seen in Figure 2, instabilities can be created two ways. As a magnetic field penetrates the superconductor, it will induce currents in it that will not decay, because of the zero resistivity. If the current in the superconductor is initially at $J_{c}$, the additional current on the surface will rise above $J_{c}$, and the surface current will decay resistively. The magnetic field will then penetrate farther into the superconductor. Thus, a positive feedback system is created. As soon as the current on the surface falls to $J_{c}$ again, the resistivity will go to zero, and the current will remain constant. Although the variation of $J_{c}$ (which is constant across the superconductor) with magnetic field can generally be ignored due to its small magnitude, the variation of $J_{c}$ with temperature cannot be ignored. This is the basic cause of flux jumping. 


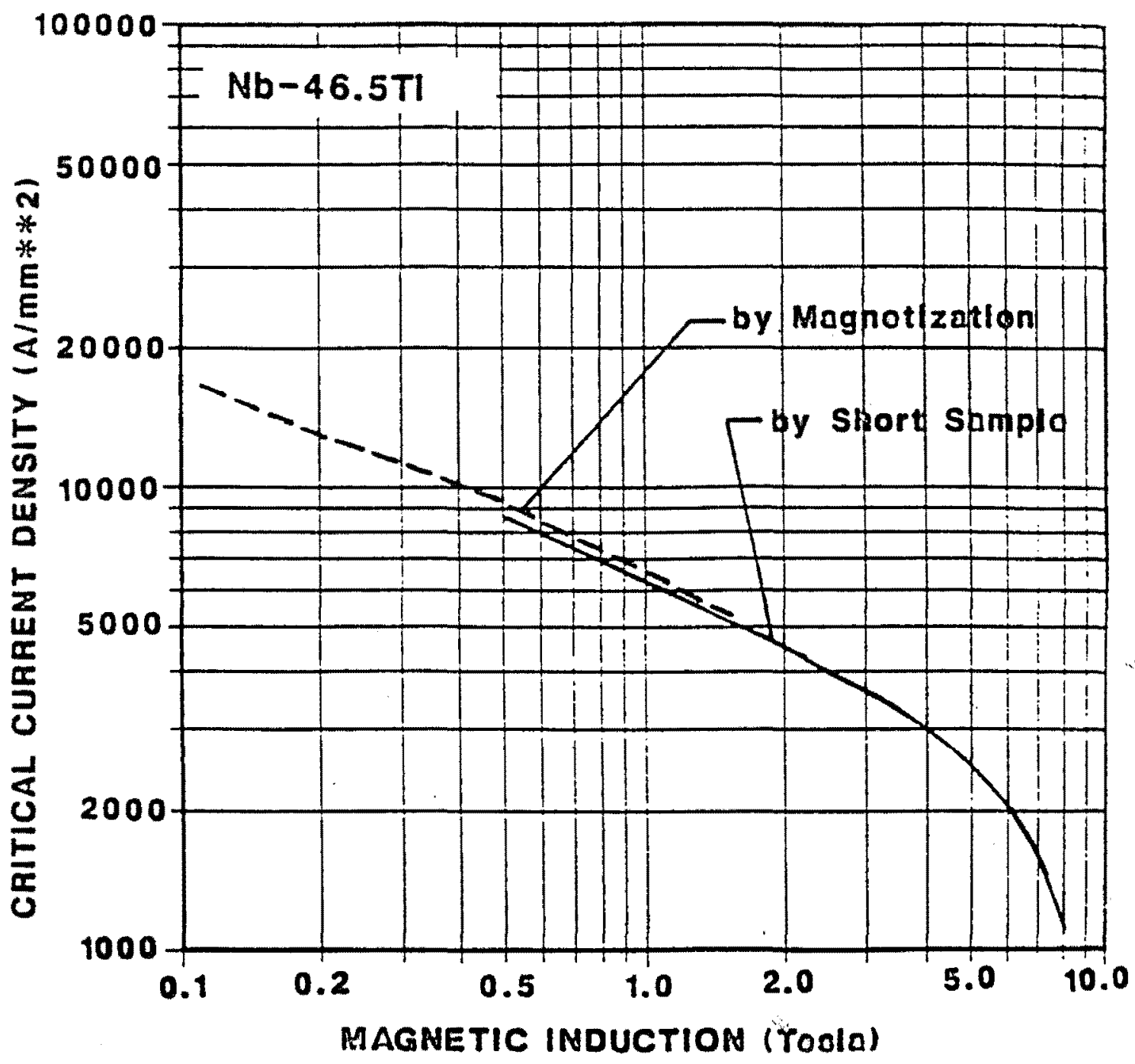

Figure 1. A typical $\mathrm{J}_{c}$ vs. $\mathrm{H}_{c}$ plot of $\mathrm{NbTi}$ at $4.22 \mathrm{~K}$. 


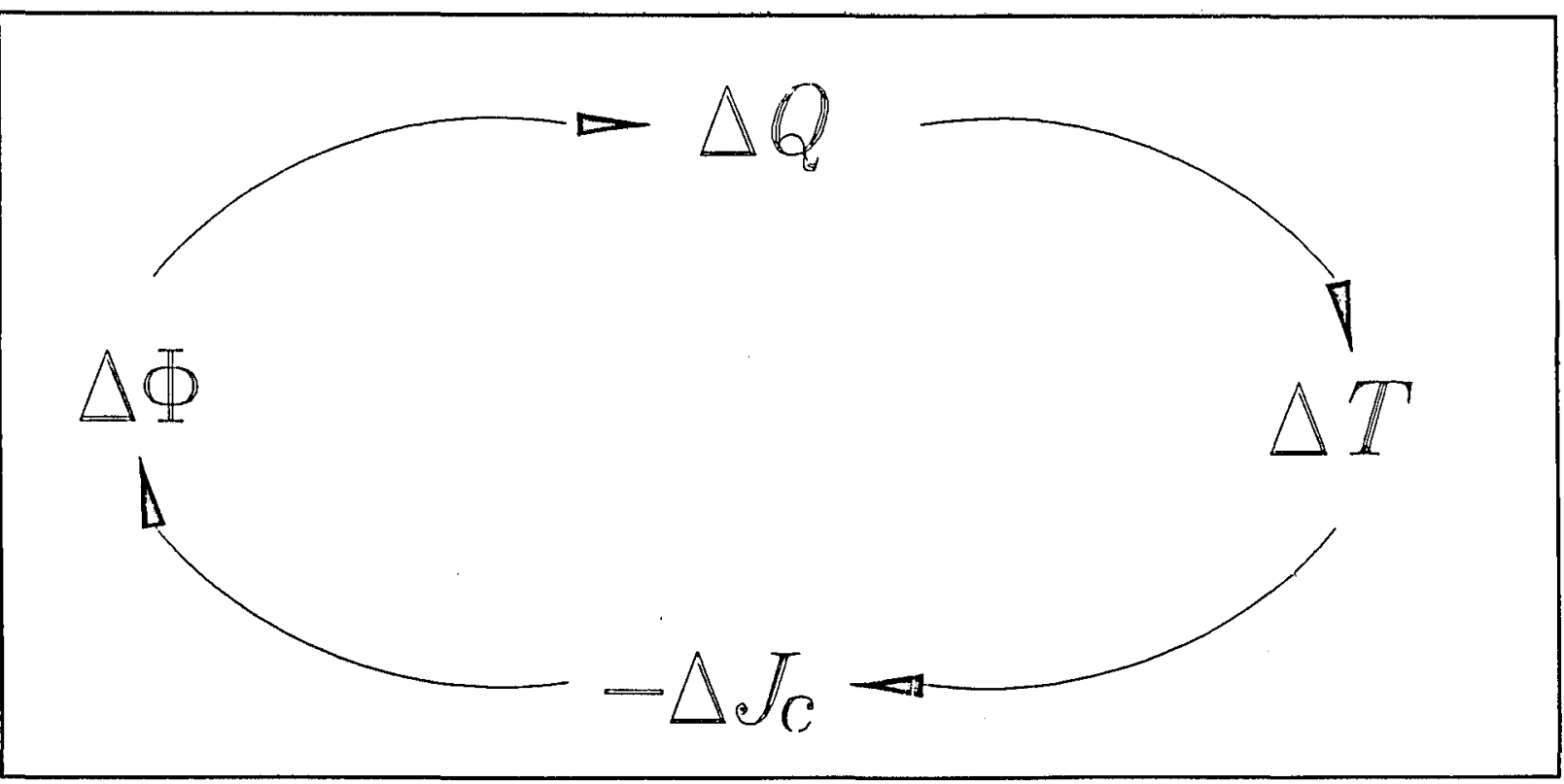

Figure 2. Illustration of positive feedback system due to flux penetration or any other heat source.

As a small heat pulse enters the superconductor, the temperature will rise, causing $J_{c}$ to fall. The magnetic field now penetrates deeper, releasing more heat. If this continues, the entire superconductor could eventually rise above $T_{c}$. There are two methods for obtaining flux jump stabilization. The first, adiabatic stabilization, is to reduce the change in flux caused by $-\Delta \mathrm{J}_{\mathrm{c}}$. The second, dynamic stabilization is to remove heat from the superconductor faster than it is produced. In the case of superconducting wires, using a twisted filamentary composite is one method for obtaining dynamic stability (Wilson 1983).

\section{Twisted Filamentary Composites}

Although flux jumping can be avoided by making superconducting wires sufficiently fine ( $s 100 \mu \mathrm{m}$ diameter), thicker filamentary composite wires are generally preferred. Unfortunately; it is quite difficult to fabricate superconducting wires of 50 to $100 \mu \mathrm{m}$ diameter. These wires would also have insulation problems and require an enormous number of turns in the coil. As a result, commercial superconductors are produced as fine filaments of superconductor within a matrix of normal metal. The metal must have high thermal and electrical conductivity and good ductility (e.g., copper, see Chapter 4).

Although good electrical conductivity is useful for preventing flux jumping, it also promotes coupling of the filaments in changing fields. If the driving voltage is great enough to overcome the resistance across the matrix, the current will travel across the 
matrix and the superconducting filaments will become coupled together. This also causes flux jumping. The characteristic distance for flux jumping is no longer the radius of the filament, but rather the composite radius.

Coupling can be reduced by twisting the composite in the longitudinal direction. An electric field is produced between the filaments from the changing external field. This electric field reverses every half twist pitch. If the twist pitch is short enough, the transverse currents will not be able to build up between the reversals. Hence, coupling will not occur (Wilson 1983).

One important parameter for multifilamentary conductors is the volume fraction of superconductor in the composite, $\mathrm{f}_{\mathrm{SC}}$ (Romanovskii 1985). Consider a composite conductor with total cross section $\mathrm{S}$ cooled to a temperature $\mathrm{T}_{0}$ over a perimeter $\mathrm{p}$ by a coolant with heat transfer coefficient $h$. The one-dimensional heat equation with thermal conduction, cooling, and resistive heating is:

$$
C_{K} \frac{\partial T}{\partial t}=k_{k} \frac{\partial^{2} T}{\partial x^{2}}-\frac{h p}{S}\left(T-T_{0}\right)+J^{2} \rho k(T)
$$

[Eq 1]

where:

$$
\begin{aligned}
& \mathrm{C}_{\mathrm{k}}=f_{s c} \mathrm{C}_{s c}+\left(1-f_{s c}\right) \mathrm{C}_{s t} \\
& \mathrm{k}_{\mathrm{k}}=f_{s c} \mathrm{k}_{s c}+\left(1-f_{s c}\right) k_{s t}
\end{aligned}
$$

and where the subscripts SC and st indicate the superconductor and the stabilizer, respectively. The temperature dependent resistivity is given as:

$$
\rho K(T)=\rho_{s t a b} \begin{cases}1 & T>T_{c}(B, J=0) \\ \frac{T-T_{c}\left(B, J_{c c}\right)}{T_{c}(B, J=0)-T_{c}\left(B, J_{s c}\right)} & T_{c}\left(B, J_{s c}\right) \leq T \leq T_{c}(B, J=0) \\ 0 & T<T_{c}\left(B, J_{s c}\right)\end{cases}
$$

where $\rho_{\text {stab }}$ is the resistivity of the stabilizer, $T_{c}(B, J=0)$ and $T_{c}\left(B, J_{S C}\right)$ are the critical temperatures at the operating field and no current density and at the operating current density, respectively. Note that the only heating in Equation 1 is due to current sharing; heating due to flux penetration is not considered. Thus, this model 
is only concerned with the response of filamentary superconductors to thermal disturbances that lead to current sharing. Flux jumping has been eliminated by fine subdivision of the superconductor.

Using Equation 1 and the equal area condition (total cooling 2 total heating) (Romanovskii 1985), the stability criterion becomes:

$$
\alpha_{j} \leq \frac{(2-j)\left(1-f_{3 c}\right)}{j^{2} f^{2} s c}
$$

where:

$$
\begin{gathered}
\mathrm{J} \equiv \frac{\mathrm{Jsc}}{\mathrm{Jc}} \leq 1 \\
\alpha_{250} \equiv \frac{J_{c}^{2} \rho_{s t a b} s}{h p\left(T_{0}-T_{0}\right)}
\end{gathered}
$$

and $J_{c}$ is the superconductor critical current density at (B, $T_{o}$ ) (Romanovskii 1985).

\section{Adiabatic Stabilization}

In an adiabatic magnet, flux jump stability does not depend on any cooling or heat removal. Instead, the conductor is able to prevent a small heat pulse from growing unstably. Adiabatic stability can only be obtained if the heat sources are reduced to very low levels, because the specific heat of materials is very small at cryogenic temperatures (Wilson 1983).

\section{Dynamic Stabilization}

In most superconducting materials, the movement of heat during a flux jump can be ignored. This is not the case, however, with filamentary composites. Methods for removing heat, current, and magnetic flux are called dynamic stability theories (Wilson 1983). Dynamic stabilization can be reached by increasing the characteristic time for flux penetration and decreasing the thermal diffusion time (Schwartz 1990). This is done by providing good contact between the superconductor and a highly conducting stabilizer and having good contact with the coolant. The stabilizer must have good electrical conductivity to slow down flux penetrations and good thermal conductivity to help carry heat away from the superconductor. Thus if a normal zone is created, the stabilizer can reduce the ohmic heat loss in the superconductor and help with normal zone recovery (Wilson 1983). 


\section{Quench Protection}

Quenching occurs when any part of a superconducting magnet changes from the superconductive state to the normal state and stability cannot be maintained. When this occurs, the normal state resistivities and current densities are both high, resulting in heat being dissipated and temperatures rising far above critical. Once this process starts, it cannot be stopped. In this instance, rapid detection of the quench is necessary so the energy can be dumped quickly. The stored energy in the magnet, $1 / 2 \mathrm{LI}^{2}$, will be lost as heat and the current must be turned off to let the magnet cool so another attempt can be made. Because the heat will not be distributed uniformly, some areas of the magnet will get much hotter than others. At the point where the normal zone starts, the temperature may rise enough to char the insulation or even melt the conductor. Even if the temperature does not rise to this point, the large voltage drops created across the normal zone can cause arcing between turns (Wilson 1983). The simplest method for protecting the magnet during a quench is to dump the current and energy into an external resistor. The equation for the heat balance is:

$$
\int_{0}^{\infty} J_{S T}^{2} d t=\int_{T_{0}}^{T_{\max }} \frac{C(T)}{\rho_{s t a b}(T)} d T \equiv s_{\text {MAX }}
$$

where $J_{s t}$ is the time dependent stabilizer current density, $t$ is the time, $C(T)$ is the temperature dependent specific heat of the stabilizer, $\rho_{s t a b}(T)$ is the stabilizer resistivity, and $\mathrm{T}_{\max }$ is the maximum peak temperature allowed during a magnet quench (about $150 \mathrm{~K}$ ). Integrating with:

$$
J_{s t}-J_{a t} \exp \left(-\frac{t}{T_{d u m p}}\right)
$$

obtains the limiting equation:

$$
S_{\max }=\frac{J_{s t}^{2} T_{d u m p}}{2}
$$

where $\tau_{\text {dump }}$ is the coil dump time constant. Furthermore,

$$
\begin{gathered}
T_{\text {dump }}=\frac{L_{\text {coll }}}{R_{\text {dump }}} \\
L_{\text {coll }} 250=\frac{2 E_{\text {storad }}}{l_{\text {pack }}^{2}}
\end{gathered}
$$




$$
R_{\text {dump }}=\frac{V_{\text {max }}}{I_{\text {pack }}}
$$

where $L_{\text {coil }}$ and $R_{\text {dump }}$ are the self inductance of the coil and the external dump resistance, $\mathrm{E}_{\text {stored }}$ is the stored energy, $\mathrm{V}_{\max }$ is the maximum voltage in each conductor turn during a quench, and $I_{\text {pack }}$ is the current in each conductor turn (winding pack). Combining Equations 10 through 13, obtains:

$$
I_{\text {pack }} V_{\text {max }} S_{\text {max }} \geq E_{\text {stored }} J_{s t}^{2}
$$

$\mathrm{V}_{\max }$ depends on the insulation properties, $\mathrm{S}_{\max }$ depends on the stabilizer properties, and $\mathrm{E}_{\text {stored }}$ results from the field strength and magnet size. Thus, quench protection implies a minimum winding pack current, $I_{\text {pack }}$, and a maximum stabilizer current density, $J_{s t}$. $I_{\text {pack }}$ is limited by conductor fabrication and the bending stresses due to the curvature of the coil. Low stabilizer current density implies a large stabilizer crosssectional area and thus a low overall magnet current density. Quench protection requirements dictate a tradeoff between compactness and fabricability (Schwartz 1990).

\section{Propagation Velocities}

When a normal zone starts to grow, heat conduction and ohmic heating will cause this zone to continue expanding. Experiments have shown that even after the initial transients have died away, the normal/superconducting boundary will continue propagating at a constant velocity (Broom and Rhoderic 1960). If the propagation velocity is too slow, the possibility exists that the energy is dissipated in one relatively small area before the quench is detected. In this case, the entire energy of the magnet may be dumped into a small volume and cause severe localized damage. On the other hand, if the normal zone propagates at a reasonable velocity, the detector can trigger a dump of the energy into an external resistor before damage occurs.

Consider a normal zone advancing through a conductor at a velocity $\mathrm{v}$ and moving from left to right. The coolant is at a temperature $T_{0}, h$ is the heat transfer coefficient, and $\mathrm{P}$ is the wetted perimeter. $\mathrm{T}_{1}$ is the equilibrium temperature where $h \mathrm{P}\left(\mathrm{T}_{1}-\mathrm{T}_{0}\right)$ $=\mathrm{G}_{\mathrm{c}} \mathrm{A}$, the critical generation. It is assumed that $\mathrm{h}$, the thermal conductivity, $\mathrm{k}$, and the specific heat, $\mathrm{C}$, are constant. Also, it is assumed that $\mathrm{G}(\mathrm{T})$ can be approximated by an abrupt transition at $\mathrm{T}_{\mathrm{s}}=\left(\mathrm{T}_{\mathrm{g}}+\mathrm{T}_{\mathrm{c}}\right)=2$ where $\mathrm{T}_{\mathrm{g}}$ is the temperature at which power generation starts in composite conductors and $T_{c}$ is the critical temperature. The normal zone boundary can then be divided into two sides split at $T_{s}$ with $G=G_{c}$ 
behind the boundary and $G=0$ in front of the boundary. For both sides the heat balance equation is:

$$
\frac{\partial}{\partial x}\left(k A \frac{\partial T}{\partial x}\right)-\gamma C A \frac{\partial T}{\partial x}-h P\left(T-T_{0}\right)+G A=0
$$

where $\gamma$ is the density of the composite. Taking $x_{s}$, the position of the boundary at $\mathrm{T}_{\mathrm{s}}$, to be the origin such that $c=x-x_{s}=x-v \mathrm{~T}$, it follows that $\partial \mathrm{T} / \partial x=-\mathrm{vdT} / \mathrm{de}$ and Equation 15 becomes:

$$
\frac{d^{2} T}{d \varepsilon^{2}}+\frac{v \gamma C}{k} \frac{d T}{d e}-\frac{h P}{k A}(T-T o)+\frac{G}{k}=0
$$

Using the boundary conditions $\mathrm{T}=\mathrm{T}_{\mathrm{s}}$ at $\mathrm{e}=0, \mathrm{~T}=\mathrm{T}_{1}$ as $\mathrm{e} \rightarrow-\infty$, and $\mathrm{T}=\mathrm{T}_{0}$ as $\mathrm{e} \rightarrow-\infty$, the temperatures on the left and right hand sides of the boundary, $T_{1}$ and $T_{r}$, are:

$$
\begin{aligned}
& T_{1}=T_{1}-\left(T_{1}-T_{s}\right) e^{\alpha / e} \\
& T_{r}=T_{0}+\left(T_{s}-T_{0}\right) e^{\alpha r e}
\end{aligned}
$$

where:

$$
\begin{gathered}
\alpha_{1}=\frac{1}{2}\left\{(\vee \vee C / k)^{2}+4 h P / k A\right\}^{1 / 2}-v \vee C / 2 k \\
\alpha_{r}=-\frac{1}{2}\left\{(\vee \vee C / k)^{2}+4 h P / k A\right)^{1 / 2}-\vee \vee C / 2 k \\
T_{1}=T_{0}+G_{c} A / h P
\end{gathered}
$$

Continuity of heat flow at the boundary must also be satisfied.

$$
-\left.k \frac{d T_{1}}{d \epsilon}\right|_{\epsilon=0}=-\left.k \frac{d T_{r}}{d \epsilon}\right|_{\epsilon=0}+v Q_{L}
$$

where $Q_{L}$ is the latent heat per unit volume. By combining Equations 17 through 22 the propagation velocity is:

$$
v\left\{\frac{k h P}{A}\right\}^{1 / 2} \cdot \frac{\left[T_{1}-T_{0}-2\left(T_{s}-T_{0}\right)\right]}{\left[Q_{L}^{2} Q_{L} Y C\left(T_{1}-T_{0}\right) Y^{2} C^{2}\left(T_{s}-T_{0}\right)\left(T_{1}-T_{s}\right)\right]^{1 / 2}}
$$


This equation shows how a high $\mathrm{k}$ will help provide quench protection by increasing v. Also, the effect of using superconductors at liquid nitrogen temperatures can be seen. At $77 \mathrm{~K}, \mathrm{C}$ will be large compared to $4 \mathrm{~K}$. This will cause $\mathrm{v}$ to decrease and quench protection will be more difficult to obtain.

\section{AC Losses}

AC losses can be studied from a macroscopic point of view. Using this model, ac losses occur from the changing of the magnetic field in a superconductor, which creates an electromagnetic field (e.m.f.) that raises the current density above $J_{c}$ and into the resistive region. In simple terms, ac losses are a form of resistance losses. On a microscopic level, ac losses occur from the viscous motion of quantized magnetic flux or fluxoids. Regardless of which method is used to model ac losses, similar results are obtained (Wilson 1983). Several components are associated with ac losses, including hysteresis losses, coupling losses, and penetration losses.

\section{Hysteresis Losses}

To more easily analyze hysteresis losses, consider a slab of superconductor with a magnetic field parallel to the slab and penetrating a distance $p$ into the superconductor. $B_{m}$ is the amplitude of the field change. The power generated, $G$, in a thin slab with thickness $d x$ and a distance $x$ out from the penetration depth, is $\mathrm{G}=$ $J_{c} \mathbf{E}=J_{c} \mathrm{~d} \phi / d t$, where $\phi$ is the change in flux enclosed. By integrating $\mathrm{J} \Delta \phi(x)$ over the slab and dividing by the volume, the loss per unit volume per half cycle can be calculated. When considering only half of the slab, use:

$$
q=\frac{1}{a} \int_{0}^{p} J_{c} \Delta \varnothing(x) d x=\frac{1}{a} \int_{0}^{p} J_{c} \mu_{o} J_{c} x^{2} d x=\mu_{o} J_{c}^{2} p^{3} / 3 a
$$

Using $p=B_{m} / 2 \mu_{0} J_{c}$ and $B_{p}$, the strength of the field that just penetrates to the center of the slab, results in:

$$
\beta=B_{m} / B_{p}=B_{m} /\left(2 \mu_{0} J_{c} a\right)
$$

By substituting Equation 25 into Equation 24 and doubling the value, the total loss per cycle is:

$$
Q=\frac{B_{m}^{2}}{2 \mu_{0}} \cdot \frac{\beta}{3}=\frac{B_{m}^{2}}{2 \mu_{0}} \Gamma(\beta) \quad \beta<1
$$


If $B_{m}>B_{p}$, the total loss per cycle is:

$$
Q=2\left(q_{1}+q_{2}\right)=\frac{B_{m}^{2}}{2 \mu_{0}}\left\{\frac{1}{\beta}-\frac{2}{3 \beta^{2}}\right\}=\frac{B_{m}^{2}}{2 \mu_{0}} \Gamma(\beta) \quad \beta>1
$$

A plot of $\mathrm{Q} /\left(\mathrm{B}_{\mathrm{m}}{ }^{2} / 2 \mu_{\mathrm{o}}\right)$ vs $\beta$ in a slab is shown in Figure 3 .

\section{Coupling Losses}

The coupling loss in a twisted filamentary composite can be determined by treating the filament as a homogeneous but anisotropic mixture (Morgan 1970). The composite is exposed to a uniform external field, $B_{e}$, that is changing at a rate of $\mathrm{Be}$. Coupling losses occur as a result of the changing flux path, following the electric center line of a filament for a certain distance but then moving through the matrix of the composite to the other side. Losses arise due to the transverse resistivity, and it has been shown that the total loss per cycle is:

$$
Q_{\theta}=\frac{B_{m}^{2}}{2 \mu_{0}} \cdot \frac{\pi \omega T}{\left(\omega^{2} T^{2}+1\right)}
$$

where $\omega$ is the angular frequency and $\tau$ is the natural time constant of the system (Wilson 1983)

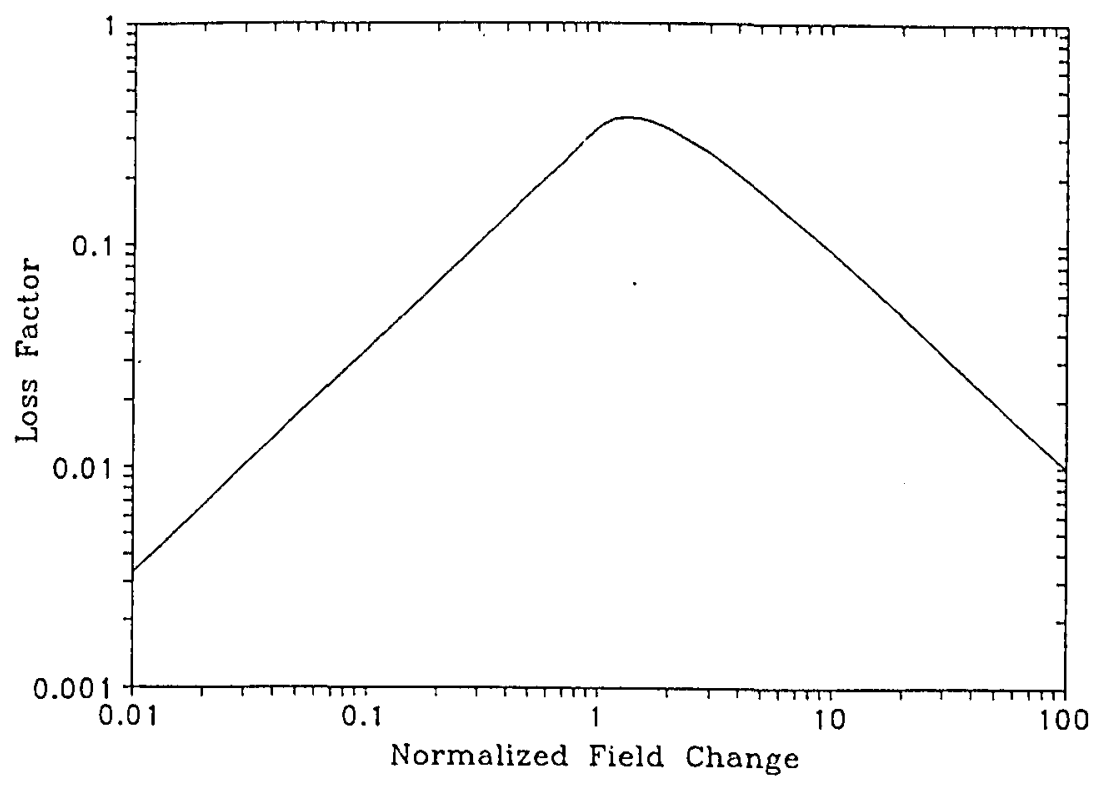

Figure 3. Loss factor $\Gamma(\beta)$ for hysteresis loss per cycle in a slab. 


$$
T=\frac{\mu_{0}}{2 \rho_{0 t}}\left(\frac{L}{2 \pi}\right)^{2}
$$

\section{Penetration Losses}

In general, the longitudinal current in a superconductor flows along the outermost filaments, which are driven to $\mathrm{J}_{c}$. This outer region is referred to as the "saturated" region. As the rate of change of the magnetic field, $B$ or the twist pitch, $L$, are increased, or the resistivity, $\rho$, is decreased, the longitudinal current also increases. As a result, the volume of the saturated region must also increase. Penetration losses occur when the longitudinal current crosses through the saturated region to the inner boundary layer (Wilson 1983). Using the condition $\mathrm{E}=0$ at the inner boundary, where $\mathrm{E}$ is the electric field, and approximating this as a hysteresis loss in a solid wire of equivalent diameter (with a current density $f_{\mathrm{SC}} \mathrm{J}_{\mathrm{c}}$ ) and having the same difference $\left(\mathrm{B}_{\mathrm{a}}\right.$ - $B_{i}$ ) between the internal and external magnetic fields, penetration losses are calculated. If a twisted filamentary composite in a ramped field (time of field ramp = $\left.T_{m}\right) B_{e}=B_{m} \tau / T_{m}$, with a difference in external fields of $B_{e}-B_{i}=B_{m} \tau / T_{m}$ is considered, there will be an equal and opposite difference during the falling part of the ramp (Ries 1977). An analogous example is a single large filament subjected to a field change of $B_{m}^{\prime}=2 B_{m} \tau / T_{m}$. If the normalized field amplitude $\beta$ is defined as:

$$
\beta=B_{m} / B_{p}=B_{m} \Pi / 4 \mu_{0} J_{c} a
$$

then the equivalent $\beta$ is:

$$
\beta^{\prime}=\frac{\pi B_{m}}{2 \mu_{o} f_{s c} J_{c} a} \cdot \frac{T}{T_{m}}
$$

By using the loss factor $\Gamma\left(\beta^{\prime}\right)$ from Equation 26, the penetration loss is:

$$
\frac{B_{m}^{\prime 2}}{2 \mu_{0}} \Gamma\left(\beta^{\prime}\right)=\frac{B_{m}^{2}}{2 \mu_{0}} \cdot \frac{4 T^{2}}{T_{m}^{2}} \Gamma\left(\beta^{\prime}\right)
$$

\section{Electromagnetic Forces}

A magnetic field exerts a force $\mathrm{F}=\mathrm{JxB}$ per unit volume of conductor. In a superconducting magnet, where both the magnetic field and current can be very high, the Lorentz forces (the combined electric and magnetic field forces) can be very large. 


\section{Stresses in Solenoids}

The strongest magnetic field in a solenoid is in the axial direction on the inside of the coil. This produces an outward radial force and causes a circumferential hoop stress in the winding. At the ends of the coil, the field has a strong radial component, and the force has a strong axial component, which compresses the winding. The component of the field on the outside of the coil reverses from the inside and produces an inward radial force. The simplest method for calculating hoop stresses in a solenoid uses the assumption that each turn acts independently and develops a tension $\mathrm{T}=\mathrm{B}(\mathrm{r}) \mathrm{I} \mathbf{r}[\mathrm{B}(\mathrm{r})$ is the magnetic flux denisity at radius $r$ and $I$ is current]. If it is assumed that the elastic properties are isotropic, the methods for distributed forces in a cylinder can be used (Timoshenko 1941). The condition for equilibrium between radial stress $\sigma_{r}$, hoop stress $\sigma_{q}$, and the body forces BJr can be expressed in a single equation using the local displacement in the radial direction $u$ as the working variable.

$$
\frac{1}{r} \frac{d}{d r}\left\{r \frac{d u}{d r}\right\}-\frac{u}{r^{2}}=-\frac{\left(1-v^{2}\right)}{Y} B J
$$

with:

$$
\begin{aligned}
& \sigma \theta=\frac{Y}{1-V^{2}}\left\{\frac{u}{r}+v \frac{d u}{d r}\right\} \\
& \sigma_{r}=\frac{Y}{1-V^{2}}\left\{\frac{d u}{d r}+v \frac{u}{r}\right\}
\end{aligned}
$$

where $\mathrm{Y}$ is the Young's modulus, $v$ is Poisson's ratio, and tensile stress is defined to be positive (Lontai and Marston 1965).

\section{Stresses in Toroids}

The magnetic field within the bore of a toroid varies inversely with the major radius. As a result, the coils are subject to strong bending forces. As the field is increased, the net force on the coils will be toward the center of the toroid because the field is strongest there. By placing a structure inside the toroid and flattening a section of the coil so it lies against this structure, the only bending forces will be on the inside and the rest of the coil will be in pure tension. The condition for equilibrium for a toroid 
is $\mathrm{T}=\mathrm{B}(\mathrm{R}) \mathrm{I} \rho=$ constant, where $\rho$ is the local radius of curvature of the coil. Using cylindrical coordinates with the z-axis lying along the torus,

$$
\rho=\frac{\left\{1+\left(\frac{d R}{d z}\right)^{2}\right\}^{3 / 2}}{d^{2} R / d z^{2}}=\frac{T R}{B_{0} R_{0} l}=K R
$$

where $\mathrm{K}$ is the constant $\mathrm{T} / \mathrm{B}_{0} \mathrm{R}_{0} I$ and $\mathrm{R}_{0}$ is the radius at which $\mathrm{d} z / \mathrm{dR}=0$ (File, Mills, and Sheffield 1971). It is not possible to obtain a complete analytical solution so numerical methods must be used; however, information about the shape of the coil can be obtained in one step of integration by substituting $\mathrm{P}=\mathrm{dR} / \mathrm{d} z$,

$$
R \frac{d^{2} R}{d z}=R P \frac{d P}{d R}=\frac{\left(1+P^{2}\right)^{3 / 2}}{K}
$$

which has the solution:

$$
P^{2}=\frac{K^{2}}{\left[\ln \left(R / R_{0}\right)\right]^{2}}-1
$$

The inner and outer radii of the toroid occur at the points where $\mathrm{dR} / \mathrm{d} z=\mathrm{P}=0$,

$$
\begin{aligned}
& R_{1}=R_{0} e^{-k} \\
& R_{2}=R_{0} e^{-k}
\end{aligned}
$$

Although this analysis only considers one current filament of infinitesimal thickness, it provides a very close estimate to computer-generated solutions, that give zero shear stress for coils with finite thickness (Wilson 1983). 


\section{Superconducting Magnet Materials}

The selection of superconducting, stabilizing, and structural materials plays a key role in the design of an SMES system. In this section, the broad range of options are discussed. Both commercially available and developmental materials are reviewed.

\section{Superconductors}

In January 1992, the only commercially available superconducting materials were $\mathrm{NbTi}$ and NbSn and its ternary compounds. The critical temperatures of these materials are approximately $10 \mathrm{~K}$ and $19 \mathrm{~K}$, respectively. As a result, the only practical coolant is liquid helium at $4.2 \mathrm{~K}$ or $1.8 \mathrm{~K}$ (Schwartz 1990). In this review, properties at $4.2 \mathrm{~K}$ will be emphasized.

\section{$\mathrm{NbTi}$}

$\mathrm{NbTi}$ is the most commonly used superconducting material. It has good ductility, which simplifies magnet construction. The $\mathrm{T}_{\mathrm{c}}$ is approximately $10 \mathrm{~K}$, and the $\mathrm{H}_{\mathrm{c}}$ is about $14 \mathrm{~T}$. If a temperature of $1.8 \mathrm{~K}$ is used, the operational limit for the field becomes approximately $12 \mathrm{~T}$ (Green 1988). Tests have recently been done in France comparing $J_{c}$ at $1.8 \mathrm{~K}$ and $4.2 \mathrm{~K}$. It was determined that $J_{c}$ is inversely dependent on the filament diameter. Also, an increase of more than $3 \mathrm{~T}$ was obtained when the temperature was decreased from $4.2 \mathrm{~K}$ to $1.7 \mathrm{~K}$. For a wire with a diameter of 1.29 $\mathrm{mm}, \mathrm{J}_{\mathrm{c}}$ ranged from 1150 to $1208 \mathrm{~A} / \mathrm{mm}^{2}$ at $4.2 \mathrm{~K}$ and $8 \mathrm{~T}$. At $1.7 \mathrm{~K}$ and $11 \mathrm{~T}, \mathrm{~J}_{\mathrm{c}}$ ranged from 1225 to $1289 \mathrm{~A} / \mathrm{mm}^{2}$. The effects of coating the wire with tin was also examined. These tests were done at $1.8 \mathrm{~K}$, and it was shown that $\mathrm{J}_{\mathrm{c}}$ only decreased by about 1 percent relative to a bare wire (Ky 1991).

\section{NbSn}

The only other commercially available superconductors are NbSn and its ternary compounds (mainly $\mathrm{NbSn}(\mathrm{Ti})$ and $\mathrm{NbSn}(\mathrm{Ta})$ ). $\mathrm{NbSn}$ has a $\mathrm{T}_{\mathrm{c}}$ and $\mathrm{H}_{\mathrm{c}}$ of about $19 \mathrm{~K}$ and 27 to $29 \mathrm{~T}$, respectively; however, these values can vary due to several factors such as the production method, ternary compounds, and neutron irradiation (Broom and Rhoderic 1960). Recent results from Japan compare the $H_{c}$ and $J_{c}$ of bronze processed 
wires at $4.2 \mathrm{~K}$ and $2.0 \mathrm{~K}$. In this study, $\mathrm{T}_{\mathrm{c}}$ was approximately $17.3 \mathrm{~K}$ and $\mathrm{H}$ was approximately $25 \mathrm{~T}$ for $\mathrm{NbSn}$ wires. For the $(\mathrm{Nb}, \mathrm{Ti})_{3} \mathrm{Sn}$ wires, $\mathrm{T}_{\mathrm{c}}$ was $16.8 \mathrm{~K}$ for a 1.0 $\mathrm{mm}$ wire and 17.1 to $17.3 \mathrm{~K}$ for a $0.3 \mathrm{~mm}$ wire. $\mathrm{H}_{\mathrm{c}}$ was about $28 \mathrm{~T}$ for both diameters. These values varied slightly with the filament twist. $H_{c}\left(J_{c}=100 \mathrm{~A} / \mathrm{mm}^{2}\right)$ at $4.2 \mathrm{~K}$ and $2.0 \mathrm{~K}$ was compared for the $\mathrm{NbSn}$ and $(\mathrm{Nb}, \mathrm{Ti})_{3}$ wires. At $4.2 \mathrm{~K}, \mathrm{H}_{\mathrm{c}}\left(100 \mathrm{~A} / \mathrm{mm}^{2}\right)$ was 17.2 $\mathrm{T}$ for $\mathrm{NbSn}$ and $19.3 \mathrm{~T}$ for $(\mathrm{Nb}, \mathrm{Ti})_{3} \mathrm{Sn}$. At $2.0 \mathrm{~K}, \mathrm{H}_{\mathrm{c}}$ increased to $21.0 \mathrm{~T}$ for $(\mathrm{Nb}, \mathrm{Ti})_{3}$ Sn for the same $J_{c}$ (Watanabe, Noto, and Muto 1991).

\section{NbAI}

Another possibility is $\mathrm{NbAl}$ for which production methods exist but are not perfected. The progress has slowed as a result of the discoveries of high-T $\mathrm{T}_{\mathrm{c}}$ superconductors. $\mathrm{H}_{\mathrm{c}}$ is about $34 \mathrm{~T}$ and $J_{c}$ is greater than $100 \mathrm{~A} / \mathrm{mm}^{2}$ in magnetic fields up to $31 \mathrm{~T}$ when tapes are used (Togano and Tachikawa 1988). Due to the reduced magnetic field, $\mathrm{Nb}$ Al is less sensitive to mechanical strain than NbSn (Ekin 1984).

\section{$V_{2}(H f, Z r)$}

One superconductor that has a comparable $J_{\mathrm{c}}$ to $\mathrm{NbAl}$ at moderate fields is $\mathrm{V}_{2}(\mathrm{Hf}, \mathrm{Zr}$ ). Although it has a relatively low $\mathrm{T}_{\mathrm{c}}$ (about $10 \mathrm{~K}$ ), it may be a plausible material for fields in the range of 12 to $16 \mathrm{~T}$ due to its insensitivity to strain (Kuroda et al. 1983).

\section{$H i g h-T_{c}$ Superconductors}

The final group of superconductors considered is high- $\mathrm{T}_{\mathrm{c}}$ ceramics. As of January $1992, \mathrm{~T}_{\mathrm{c}}$ as high as $125 \mathrm{~K}$ is regularly obtained; however, high $\mathrm{J}_{\mathrm{c}}$ at $77 \mathrm{~K}$ (the boiling point of liquid nitrogen) and in a magnetic field greater than $1 \mathrm{~T}$ has not been obtained. $J_{c}$ greater than $1000 \mathrm{~A} / \mathrm{mm}^{2}$ at $20 \mathrm{~K}, 20 \mathrm{~T}$ has been obtained in short thick tapes. Also, there is no method at the present for producing long, homogeneous lengths of superconductor (Bobrov 347).

\section{Stabilizers}

As discussed in Chapter 3 , the safe operation of a superconducting magnet requires that the superconducting filaments be surrounded by a high purity, highly conducting normal metal, known as a stabilizer. The stabilizer must be in close contact with the superconductor at all times to absorb the heat and conduct it to the coolant while minimizing heat generation during a disturbance. 
The most commonly used stabilizers are high purity copper $(\mathrm{Cu})$ and aluminum $(\mathrm{Al})$. At low magnetic fields, $\mathrm{Cu}$ has the lower resistivity and can be processed easily with $\mathrm{NbTi}$ and NbSn. Al has a lower magnetoresistivity and is less expensive when very high purity is required (Schwartz 1990).

Composite materials with a $\mathrm{Cu}$ or $\mathrm{Al}$ matrix may be higher strength options. These will have a higher strength and a higher modulus than pure metals. The two primary choices are $\mathrm{CuNb}$ microcomposite and a uniaxially reinforced $\mathrm{Al}$ matrix composite containing high strength fibers (e.g., $\mathrm{SiC}, \mathrm{C}$, or S-glass). CuNb has better than rule-of-mixtures strength with very high electrical conductivity and has been wound into a $68.4 \mathrm{~T}$ pulsed coil (Foner 1986). Al-SiC also has very good electrical conductivity and a higher tensile strength than $\mathrm{CuNb}$; however, it has never been used in a magnet application (Buck 1987).

\section{Structural Metals}

A wide variety of high strength metals are candidates for an SMES magnet system. They are summarized in Table 6; the tensile stress is shown in giga Pascals.

\section{Cryogenic Steels}

Table 6. Structural metals.

\begin{tabular}{|l|c|}
\hline Material & $\mathbf{S}_{\mathrm{m}, \mathrm{T}}(\mathrm{GPa})$ \\
\hline Cryogenic steels & $1.6-2.0$ \\
\hline Maraging steels & $2.2-3.7$ \\
\hline Titanium alloys & 1.9 \\
\hline
\end{tabular}

Cryogenic steels (SS304, SS316, JBK-75, Incoloy 908, Fe-Mn and Fe-Cr alloys) have an ultimate tensile stress $\left(\mathrm{S}_{\mathrm{m}, \mathrm{T}}\right)$ of 1.6 to $2.0 \mathrm{GPa}$. SS304 and SS316 are very well characterized as a result of widespread use in industry. The strength and toughness of these two materials depend greatly on specific alloying and heat treatment. The properties of JBK-75 are also well known because of its similarity to alloy A286, which has been commercially available for over 20 years (Neef 1988; Morris and Dalder 1985). The Fe-Cr-Ni and Fe-Mn-Cr alloys were developed in Japan specifically for cryogenic uses (Suemune et al. 1988; Nakajima et al. 1988). These alloys are distinguished by high strength and fracture toughness at liquid helium temperatures.

Although Incoloy 908, developed at Massachusetts Institute of Technology, was still in the testing stages in early 1992, it has the best combination of strength and toughness when it is cold worked and then aged (Martin et al. 1988; Morra et al. 1989). It is characterized by a very low coefficient of thermal expansion (equal to that of $\mathrm{NbSn}$ ), which greatly reduces the thermal strain in the superconductor. At $4 \mathrm{~K}$ this alloy is very ductile and is both workable and weldable. It contains approximately 41 percent $\mathrm{Fe}$ and 49 percent $\mathrm{Ni}$. Precipitating $\mathrm{Ni}_{3}$ (Al,Ti) during heat treatment gives 
it its high strength. NbSn has a similar heat treatment schedule, which makes this alloy an ideal magnet material (Schwartz 1990).

The performance of Incoloy 908 in a NbSn magnet has been demonstrated by the United States Demonstration Poloidal Coil, US-DPC, which also completed testing in Japan. In this coil, the NbSn performance was enhanced due to the lack of thermally induced strain.

\section{Maraging Steels}

Another commercially available group of structural metals are the Ni-Co and Ni-Ti maraging steels. The cryogenic $\mathrm{S}_{\mathrm{m}, \mathrm{T}}$ ranges from 2.2 to $3.7 \mathrm{GPa}$ depending on the composition and aging of the steel (Corn 1966; Teledyne Vasco 1982). These commercial steels are referenced by four different grades: 200, 250, 300, and 350, where the grade refers to the room temperature strength in ksi. The 350 grade maraging steels have very low fracture toughness and would not be applicable for SMES use. The 300 grade maraging steels have Sm,T approximately equal to $3.1 \mathrm{GPa}$ at $4.2 \mathrm{~K}$, providing an allowable stress depending on strain to failure. If the 300 grade has insufficient ductility, the 250 grade can be considered. The cryogenic $S_{m, T}$ of this grade is around 2.6 GPa (Schwartz 1990).

\section{Titanium Alloys}

Certain Ti alloys may also be good materials for cryogenic applications. A yield stress as high as $1892 \mathrm{MPa}$ has been found at $4.2 \mathrm{~K}$, although with a low fracture toughness. The fracture toughness can have a sizable increase by selecting an alloy with lower strength ( $\sigma_{y}$ approximately $1640 \mathrm{MPa}$ ) (Nagai et al. 1988). The aerospace industry has significant experience with $\mathrm{Ti}$, so it may become a possible alternative in the near future (Schwartz 1990).

\section{Composites}

Composite materials have the ability to obtain higher strength, stiffness, and fracture toughness than metals. Furthermore, they allow the engineer to "design" the material best suited to the requirements of the application.

\section{Matrix}

Generally, an aluminum or epoxy matrix is used for composites. These lead to very good strength to weight ratios, and have widespread use in the aerospace industry. 
Due to the relatively low compressive strength of most fibers, the compressive loads must be supported by incorporating the fibers into a matrix. The only method that can obtain high strength in all directions is to use metal matrix composites such as Al-SiC. Although this makes a good stabilizer, it is not satisfactory for structural material (Schwartz 1990). Thus, for high field superconducting magnet applications, the high strength steels discussed earlier will be considered as candidate matrix materials.

\section{Fiber}

Fibers can have a longitudinal tensile strength $\left(\mathrm{S}_{\mathrm{n1}, \mathrm{T}}\right)$ ranging from 2.1 to $7 \mathrm{GPa}$ and a longitudinal modulus $\left(\mathrm{E}_{\mathrm{n} 1}\right)$ from 125 to $900 \mathrm{GPa}$. The most common fibers (Table 7) are polymers, boron (B), silicon carbide ( $\mathrm{SiC}$ ), and carbon (C) (Morris 1988; Allen, Farris, and Thomas 1985;

Table 7. Fibers for composites. Dupont Kevlar undated; Hamada et al.

\begin{tabular}{|l|c|c|}
\hline Fiber & $\mathbf{S}_{11, \pi}(\mathrm{GPa})$ & $\mathrm{E}_{\mathrm{n}}(\mathrm{GPa})$ \\
\hline Polymers & 3.6 & 175 \\
\hline Boron & 3.6 & 400 \\
\hline Silicon carbide & $>3.5$ & 430 \\
\hline Carbon & $\geq 7.0$ & 900 \\
\hline
\end{tabular}
1987; Avco Specialty Materials 1988a, 1988b).

Polymers. The series of Kevlar fibers produced by DuPont are the most widely used fibers in composite applications. These have obtained $\mathrm{S}_{\mathrm{f1} 1, \mathrm{~T}}$ of approximately $3.6 \mathrm{GPa}$ and $\mathrm{E}_{\mathrm{f} 11}$ of approximately $175 \mathrm{GPa}$ (Dupont Kevlar undated). Another possibility, which is still in the developmental stages, is heat treated, wet-spun poly-(p-phenylene benzobisthiazole) (PBT) fiber. This has obtained $\mathrm{S}_{\mathrm{f1}, \mathrm{T}}$ of about $3 \mathrm{GPa}$ and $\mathrm{E}_{\mathrm{f} 11}$ of about $300 \mathrm{GPa}$ (Schwartz 1990).

Boron. Boron fibers have been used extensively in the aerospace industry but have had little testing at cryogenic temperatures. Boron fibers (diameter about $100 \mu \mathrm{m}$ ) with $\mathrm{S}_{\mathrm{f1}, \mathrm{T}}$ about $3.6 \mathrm{GPa}$ and $\mathrm{E}_{\mathrm{f11}}$ about $400 \mathrm{GPa}$ are commercially available (Buck 1987; Avco Specialty Materials 1988a).

Silicon carbide. Avco Specialty Materials has developed SiC fibers with good mechanical and thermal properties using chemical vapor deposition (CVD) onto carbon. Fibers with a diameter of $140 \mu \mathrm{m}$ and $\mathrm{S}_{\mathrm{f1}, \mathrm{r}}$ greater than $3.5 \mathrm{GPa}$ and $\mathrm{E}_{\mathrm{f} 11}$ about $430 \mathrm{GPa}$ have been produced. These fibers maintain good properties from cryogenic temperatures to $\mathrm{T}$ approximately $600^{\circ} \mathrm{C}$ and maintain very high strength at $\mathrm{T}$ approximately $800^{\circ} \mathrm{C}$ (Avco Specialty Materials 1988b).

The largest problem with SiC fibers is the cost and production rate, CVD is a slow process, resulting in high-cost fibers. Pyrolysis is an alternative method and produces 
fine, flexible fibers commercially known as Nicalon (Anderson and Warren 1984). Even though Nicalon is much less expensive, the quality of the fiber is noticeably lower with $\mathrm{S}_{\mathrm{f} 11, \mathrm{r}}$ greater than $2 \mathrm{GPa}$ and $\mathrm{E}_{\mathrm{fl} 1}$ about $200 \mathrm{GPa}$ (Schwartz 1990).

Carbon. Carbon has the best combination of mechanical properties, availability, cost, and applicability of all the available fibers. These fibers have obtained $S_{i 11, \mathrm{~T}}$ greater than or equal to $7 \mathrm{GPa}$ and $\mathrm{E}_{\mathrm{f} 11}$ about $900 \mathrm{GPa}$ (not simultaneously) (Hamada et al. 1987; Toray Industries 1988; Dupont 1989). These fibers are inherently anisotropic with $\mathrm{E}_{\mathrm{R} 22}$ less than $0.1 \mathrm{E}_{\mathrm{f} 11}$, where $\mathrm{E}_{\mathrm{f2} 22}$ is the transverse Young's modulus. As a result, the fibers can support very high tensile loads and still allow the matrix to absorb most of the radial load (Schwartz 1990). 


\section{Toroidal SMES Analysis}

Toroidal magnet analysis will be based upon a toroidal array of identical D-shaped coils (e.g., constant tension Princeton-D, see Figure 4) (Gray, Stoddard, and Akin 1979). This analysis will focus on the layout of the inner leg as this is the most constrained region. A typical cross-section of the inner leg is shown in Figure 5. Conductors are located within the grooves shown in this cross-section. A typical unit cell, including structure, conductor, and coolant, is shown in Figure 6. This form of integrated structure represents either structure wound with the conductor (as in a Cable-In-Conduit Conductor), or conductor wound into grooved plates. Several parameters such as the winding pack current, stabilizer properties, and structure thermal contraction were varied (within appropriate constraints) to minimize the total cost.

A geometry in which the toroidal dimension of the unit cells is fixed was used. This eliminates misalignment of rows (rows refer to the toroidal direction; i.e., constant magnetic field, see Figure 5). If the minimization was broad, parameters were selected to minimize either the radial dimension of the largest turn ( $\mathrm{s}_{\mathrm{rad}}$, see Figure 6 ) or the stress in the stabilizer, $\sigma_{\mathrm{st}}$. To prevent excessive bending, the peak bending strain, which occurs at the point of minimum stress (the inside of the inner leg), never exceeded 1 percent. However, the strain throughout the rest of the coil was much lower.

The importance of the total thermal expansion of the structure has been previously demonstrated (see Figure 7 ). The radial build and $s_{\mathrm{rad}}$ are plotted vs. $\frac{\delta l}{l}(300 \mathrm{~K}-4 \mathrm{~K})$ of the conduit relative to the magnet case. This is the only variable that reduces both the radial build and $\mathrm{s}_{\mathrm{rad}}$ simultaneously. The maximum relative expansion is chosen to be $-10^{-3}$ (total expansion $=-2 \times 10^{-3}$ ), in order to match conduit wall expansion to that of the superconductor. Although it would be desirable to allow more precompression in the integrated structure (i.e., plate or conduit), this may over-strain the superconductor. Within each magnet, 1 to 5 grades of conductor were used (depending upon $\mathrm{B}_{\max }$ ). This allows the conductor in the high field region to be optimized independently of the optimization of the low field conductor. Within each pancake coil (e.g., within a single plate), the grades are joined with very low loss joints in the outer leg of the coil. Typical maximum fields for grades within a single coil are listed in Table 8. 


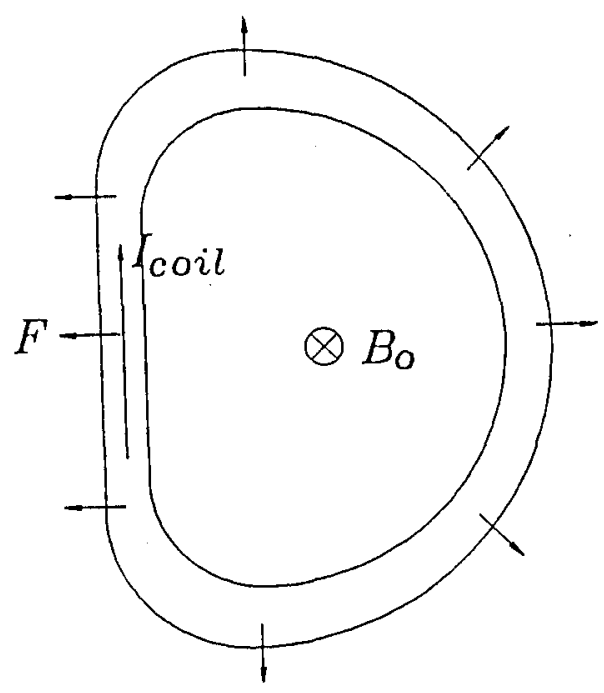

Figure 4. Constant-tension Princeton-D geometry.

Conductor Grade: $\begin{array}{lllll}5 & 4 & 3 & 2\end{array}$

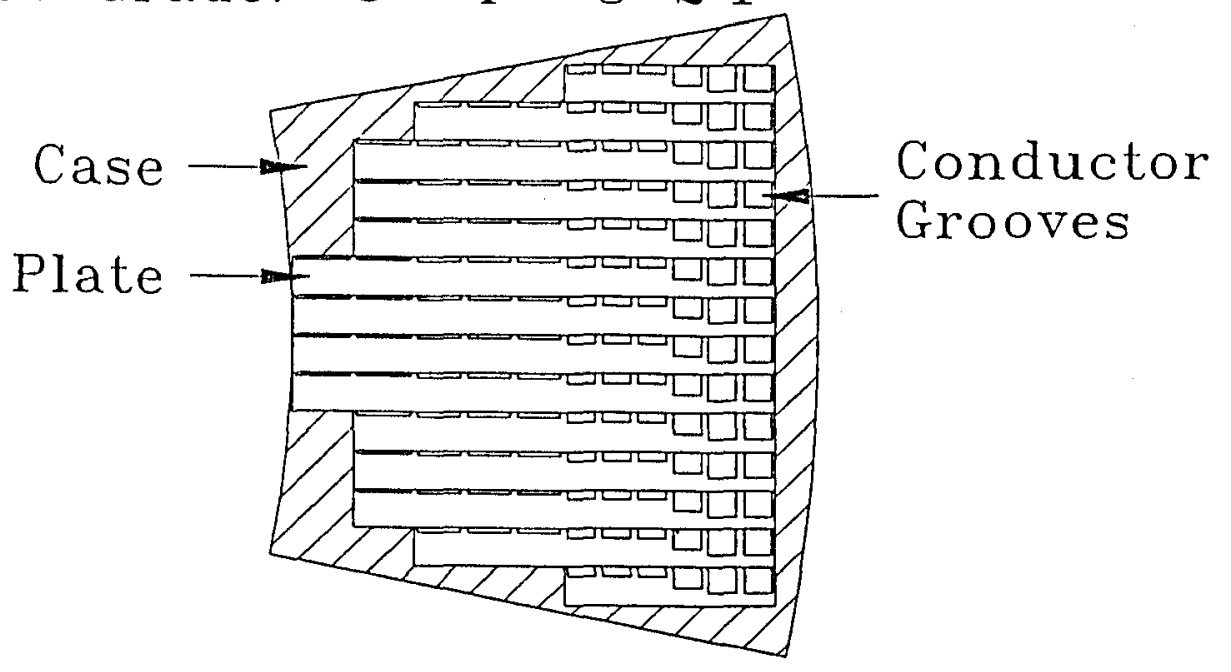

Figure 5. Inner-leg cross section with fixed toroidal dimension. 


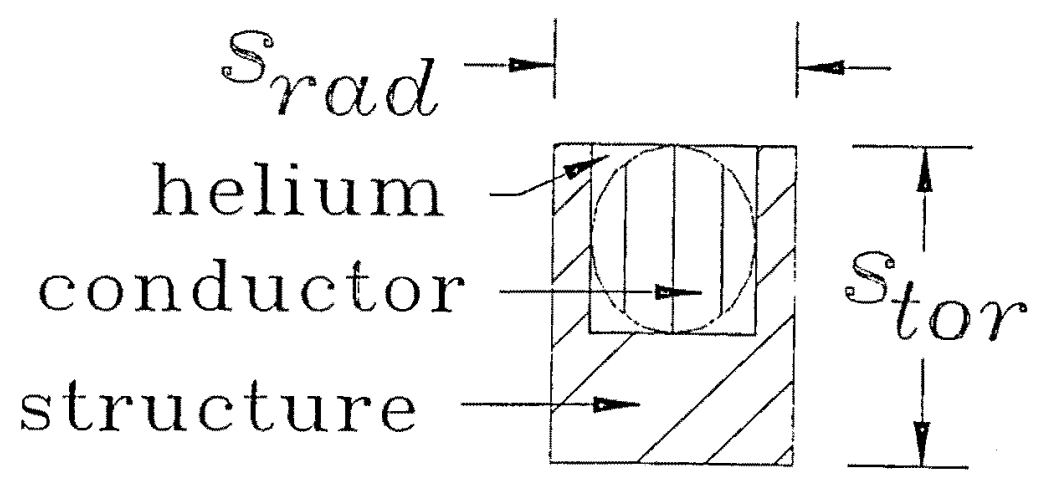

Figure 6. Typical conductor unit cell.

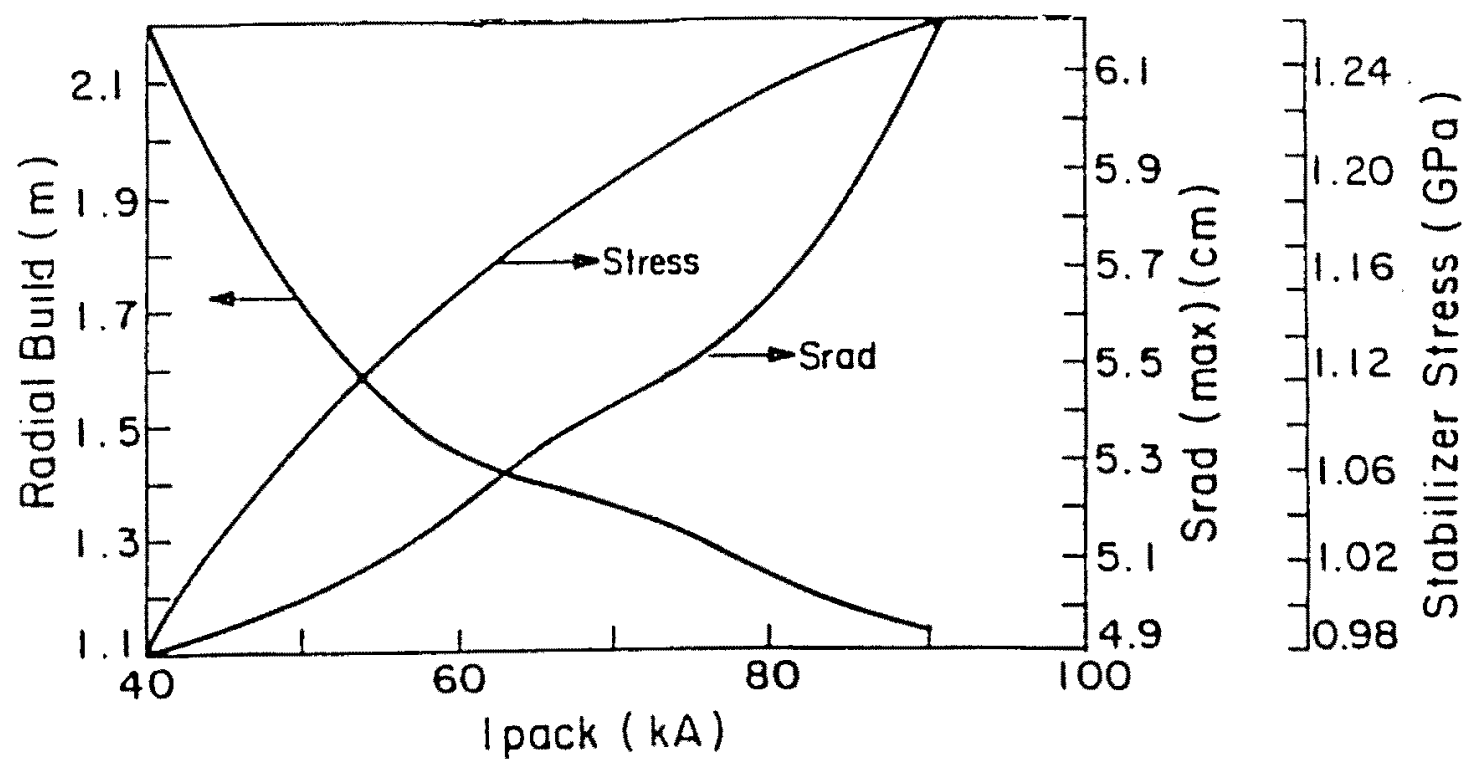

Figure 7. Radial build and $s_{r a d}$ as a function of the conduit thermal expansion relative to the magnet case. 
Table 8. Typical maximum fields for grades.

\begin{tabular}{|c|c|}
\hline Grade & Maximum Field (T) \\
\hline 1 & 3.00 \\
\hline 2 & 7.11 \\
\hline 3 & 12.38 \\
\hline 4 & 17.00 \\
\hline 5 & 26.00 \\
\hline
\end{tabular}

The analysis of 10 MWh SMES systems was separated into two parts. First, a base case for further comparisons was established. Parameters for the base case were limited by presently available technology. Thus, the base case represents the best SMES system achievable in January 1992. This analysis was followed by evaluation of the potential of future technologies. In this analysis, key parameters (e.g., $J_{c}, T_{o p}$, operating stress, etc.) were varied from the base case and the impact quantified in terms of system cost.

\section{Magnetic Field and Radius at Constant Energy}

The stored energy of a toroidal magnet array is determined primarily by the magnetic field, major radius, and minor radius. The thickness of the coil plays an important but secondary role. Thus, for fixed $E_{\text {stored }}$, the surface $E_{\text {stored }}\left(B ; R_{o} ; a\right)=36 \mathrm{GJ}$ is necessary. This is determined using:

$$
E_{\text {stored }}=0.0025 \pi k R_{\text {out }}^{2} B^{2} h_{\text {avg }}
$$

where:

$$
\begin{gathered}
k=\frac{1}{2} \ln \left(\frac{R_{\text {outlog }}}{R_{\text {Inmean }}}\right) \\
R_{\text {out }}=R_{o}-a \\
h_{\text {avg }}=\frac{1}{2}\left(1.2 k R_{\text {Inmoan }}+0.89 K R_{\text {outlog }}\right) \\
R_{\text {Inmean }} \quad R_{o}-a-0.5 \text { build } \\
R_{\text {outlog }}=R_{0}+a+0.5 \text { build }
\end{gathered}
$$


and is shown in Figure 8. Here the magnetic field $B$ represents the field at $R_{0}$. The peak field at the coil is:

$$
B_{\text {max }}=B \frac{R_{0}}{R_{0}-a}
$$

From Figure 8 , for any value of $B$, there is a continuum of values for $R_{0}$ and $a$. Further analysis showed that the minimum cost was obtained at the smallest major radius feasible (see Figure 9). Equations 41 through 46 were used as a starting point for all analyses. An iterative process in $a$ was integrated into the analysis code so that magnet systems of $36 \pm 0.01$ GJ were compared.

\section{Cost Estimates}

The magnet system costs were estimated using the costing analysis routines developed for the International Thermonuclear Experimental Reactor (ITER) magnet system (developed at Lawrence Livermore National Laboratory). Only the ITER toroidal field (TF) coils were considered. The amount of energy stored in this TF magnet system (42.3 GJ) is comparable to that of this study. Material unit costs for estimating the magnet costs are shown in Table 9.

The cost of the conductor in Table 9 includes the unit cost of the superconductor, the unit cost of the stabilizer, and the costs of cabling and winding the conductor. These were determined as follows:

$$
\begin{gathered}
\mathrm{C}_{\text {sc }}=\$ 248 / \mathrm{kg} \times \mathrm{Msc} \\
\mathrm{C}_{\text {cabling }}=\$ 20 / \mathrm{m} \times \text { Length } \\
\mathrm{C}_{\text {wind }}=\$ 300 / \mathrm{m} \times \text { Length }+\$ 30 / \mathrm{kg} \times \mathrm{Msc}
\end{gathered}
$$

where:

$$
\begin{aligned}
& \mathrm{C}_{\mathrm{SC}} \quad=\text { the cost of the superconductor, } \\
& \mathrm{M}_{\mathrm{SC}}=\text { the mass of the superconductor, } \\
& \mathrm{C}_{\text {cabling }}=\text { the cost of cabling, } \\
& \text { Length }=\text { the total length of conductor } \\
& \mathrm{C}_{\text {wind }}=\text { the cost of winding the conductor. }
\end{aligned}
$$




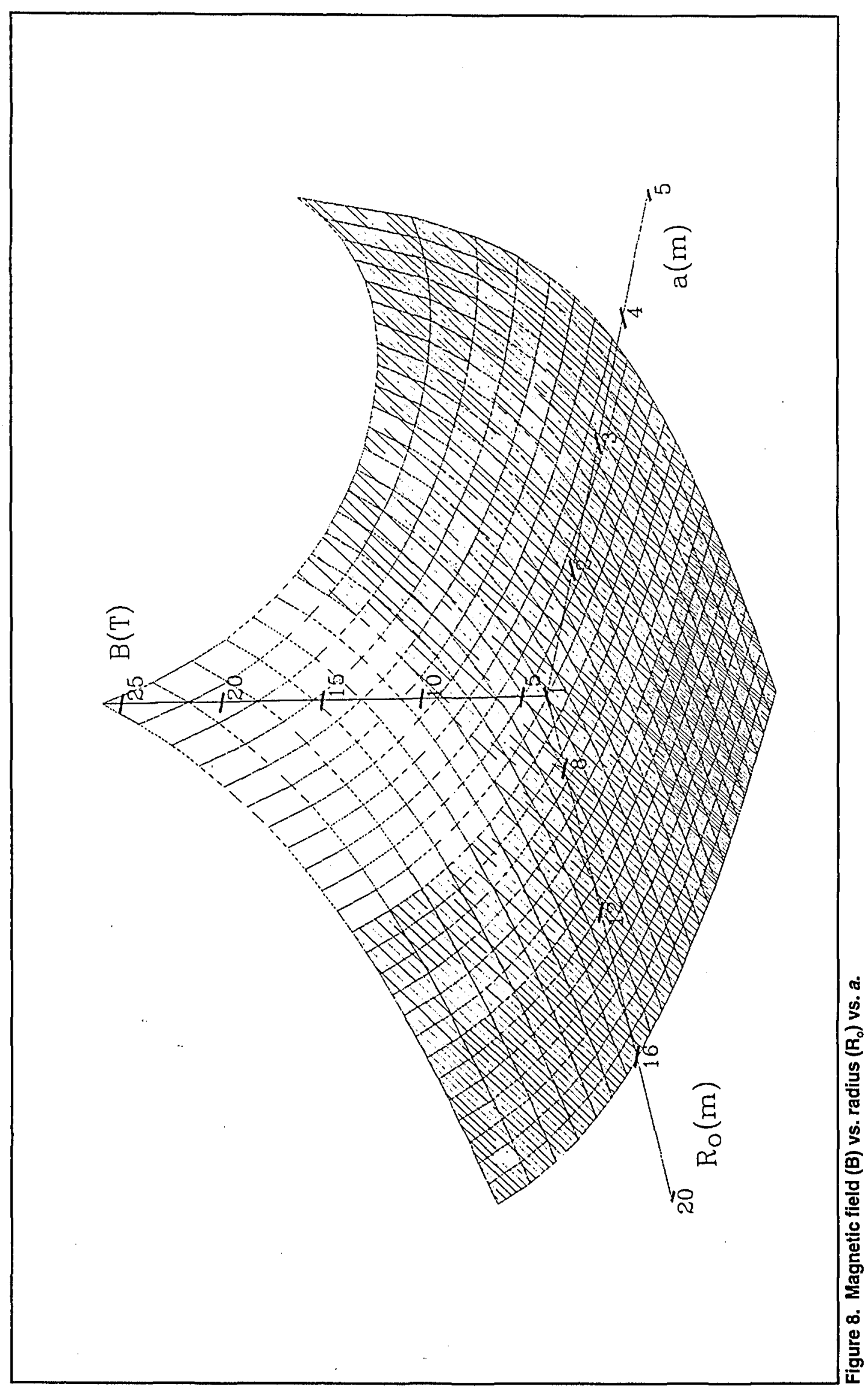




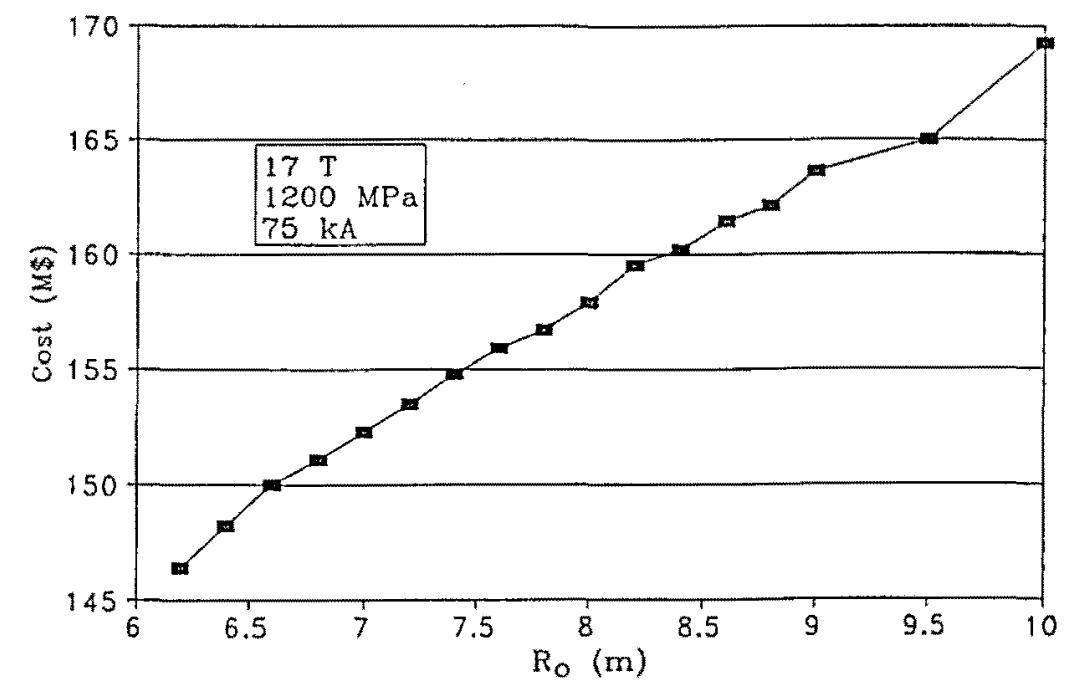

Figure 9. Typical cost vs. $\mathbf{R}_{0}$.

Table 9. Cost of materials.

\begin{tabular}{|l|l|}
\hline Material & Cost $\mathbf{( \$ / k g )}$ \\
\hline Cold Structure & 60 \\
\hline Gravity Support & 35 \\
\hline Conductor & 248 \\
\hline
\end{tabular}

The cryogenic costs were calculated using the ITER cryogenic system. Because the magnet is completely self-contained, the conduction heat load for supports was ignored in this study. Also, the intercoil structure, $\mathrm{AC}$ heating, and the neutron heating that are inherent to the ITER fusion device do not apply. The losses from current leads were scaled from ITER by taking into account the difference in currents and the total number of coils in the array. AC losses were calculated according to Wilson (1983) (see Chapter 3). After calculating the average head loads, the cryogenic costs of the ITER magnet system were scaled to obtain the estimate for the cryogenic costs for $\mathrm{T}_{\mathrm{op}}=4.2$ K. For higher temperature operation, the costs were scaled with $1 / T_{\mathrm{op}}$.

It is very important to note that the material costs in Table 9, in particular for the superconductor, are "first-of-a-kind" costs. Lower unit costs are appropriate for "10th-of-a-kind" costing. While the absolute costs would decrease dramatically, the engineering tradeoffs would not be greatly affected. Thus, although the specific values at which minima occur would shift slightly, the implications relating to the impact of advanced technology would not be altered. 


\section{Identification of Base Case}

To assess the impact of advanced technologies, a base case set of system parameters was necessary. The base case was determined by minimizing the cost (using presently available materials) while varying $I_{\text {pack }}$ and the magnetic field. Other parameters such as $s_{t o r}, V_{\max }$, and the number of coils in the toroidal array were also selected based upon best available materials and cost minimization.

\section{Selection of Base Case Materials}

Only currently available and well understood materials were candidates for the base case. NbTi was selected for the conductor for fields below $6 \mathrm{~T}$ and $\mathrm{NbSn}$ is selected at all other fields. As these are the only commercially available superconductors, the only issue was at which magnetic field does $\mathrm{NbSn}$ become preferred. This was determined by considering $J_{c}(B)$ from the literature. Because of the choice of superconductors, liquid helium was the coolant and high purity copper or high purity aluminum was the stabilizer. Incoloy 908 was selected for the integrated structure (plates or conduit) so that the mismatch in thermal contraction with the superconductor was minimized. A286 was used for the coil casing. Due to the difference in thermal contraction between A286 and Incoloy 908, the conductor and plates are in compression after cooling to $4.2 \mathrm{~K}$. When the magnet is energized, the Lorentz-force induced tensile strain overcomes this precompression and the magnet is in tension. The precompression increases the magnitude of vertical tension that the magnet can withstand. A286 or another high strength (at room temperature) steel alloy is used for the gravity support that keeps the magnet suspended off the ground.

\section{Identification of Base Case Parameters}

The assumed base case parameters are summarized in Table 10, where $\sigma_{\text {wall }}, \sigma_{\text {case }}$, and $\sigma_{\mathrm{st}}$ are the allowed stresses in the wall, casing, and stabilizer, respectively, and $\mathrm{V}_{\max }$ is the maximum voltage in each conductor turn during a quench. Table 11 lists the fixed values of the Young's modulus, thermal expansion, and allowed stresses for the structural materials. It was assumed that the conductor and insulation would support minimum load. $J_{c}$ vs. $B$ can be seen in Figure 10. In addition to the base case curve, $J_{c}(B)$ for the advanced technology analyses are shown. (This is discussed further in the following section.)

The winding pack current was varied from $25 \mathrm{kA}$ to $250 \mathrm{kA}$. At each current, $\mathrm{B}$ was varied from $3 \mathrm{~T}$ to $17 \mathrm{~T}$, and at each field, $\mathrm{R}_{0}$ (the major radius) was chosen so the cost would be minimized. This is plotted in Figure 11. Each point shown has a corresponding 
Table 10. Base case

parameters.

\begin{tabular}{|l|l|}
\hline Current $(\mathrm{kA})$ & 75 \\
\hline \# of Coils & 24 \\
\hline$\sigma_{\text {wall }}(\mathrm{Mpa})$ & 800 \\
\hline$\sigma_{\text {case }}(\mathrm{Mpa})$ & 800 \\
\hline$\sigma_{\mathrm{st}}(\mathrm{MPa})$ & 300 \\
\hline $\mathrm{s}_{\text {tur }}(\mathrm{cm})$ & 7.0 \\
\hline $\mathrm{V}_{\max }(\mathrm{kV})$ & 20.0 \\
\hline
\end{tabular}

Table 11. Materials properties.

\begin{tabular}{|l|c|c|c|c|c|}
\hline & SC & Insulator & Stabilizer & Wall & Case \\
\hline Young's Modulus (GPa) & 175 & 70 & 130 & 210 & 210 \\
\hline$\sigma_{\text {allowed }}(\mathrm{MPa})$ & - & - & 300 & 800 & 800 \\
\hline Thermal expansion $(293 \mathrm{~K}-4 \mathrm{~K}) \times 10^{-3}$ & -2.0 & -2.0 & -2.9 & -2.0 & -3.0 \\
\hline
\end{tabular}

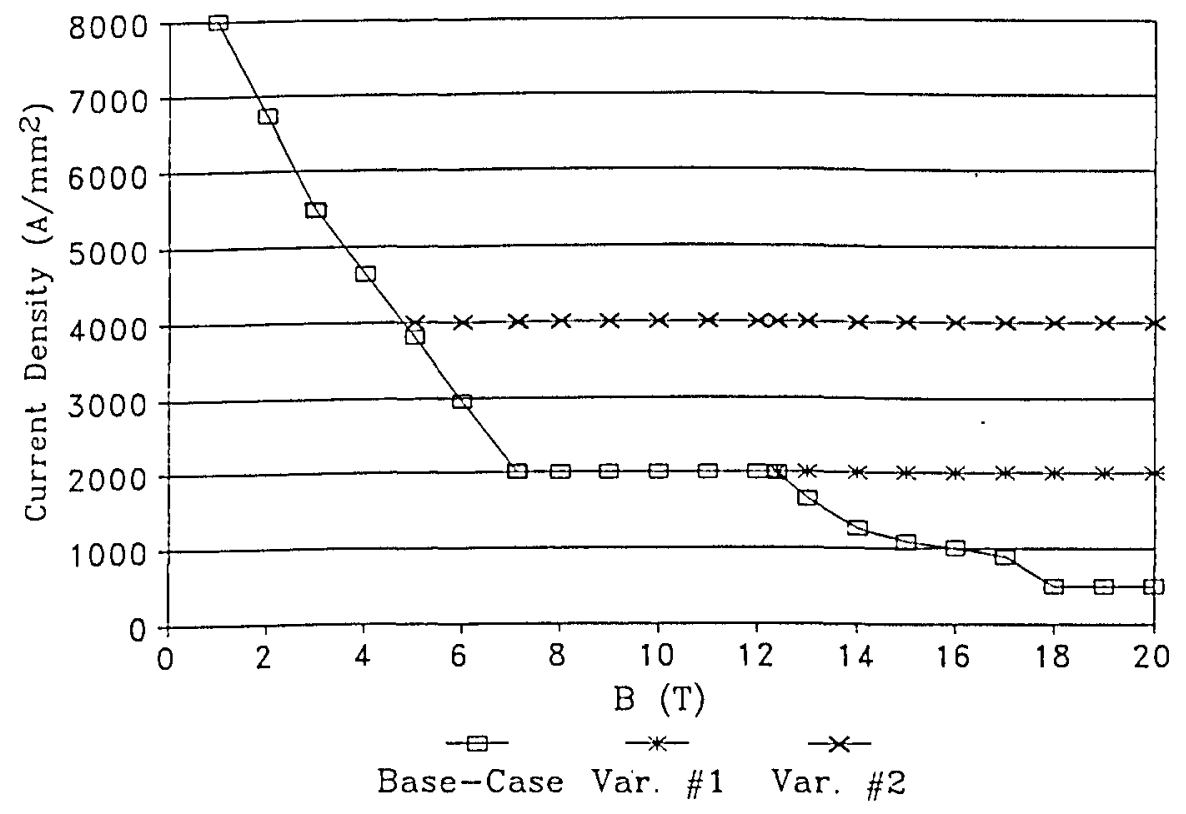

Figure 10. Current density vs. field. 


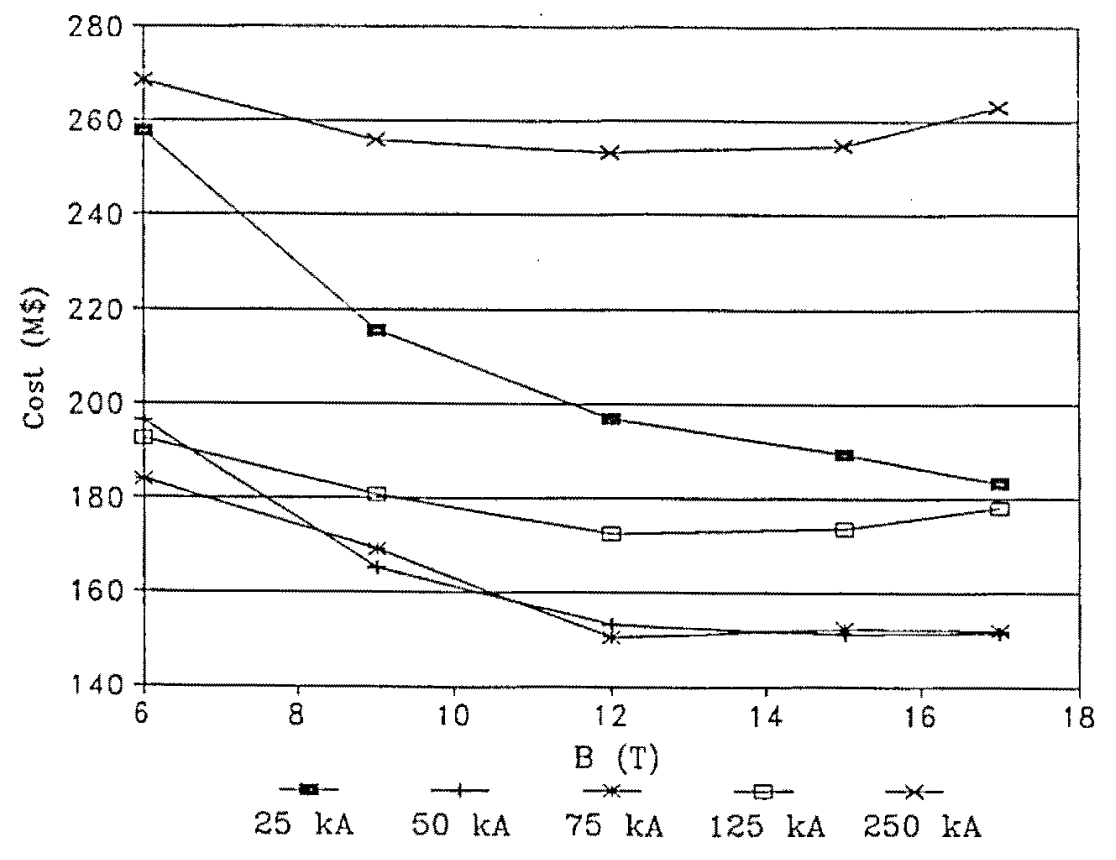

Figure 11. Cost vs. current at $4.2 \mathrm{~K}$.

$R_{0}$ and $\alpha$ that minimized the cost for that $I_{\text {pack }}, B$. Figure 11 demonstrates that at 4.2 $\mathrm{K}, \mathrm{I}_{\text {pack }}$ approximately equal to 50 to $75 \mathrm{kA}$ is optimum. Owing to the weak dependence of cost on magnetic field for $\mathrm{B}$ greater than $12 \mathrm{~T}$, the $75 \mathrm{kA}$ curve of Figure 11 represents the base case parameterization.

\section{Future Technologies}

The primary technologies that can potentially affect the cost of SMES systems significantly. include superconductor $J_{c}(B), T_{o p}$ (for fixed $J_{c}(B)$ ), $\sigma_{\text {allowed }}, I_{\text {pack }}$, and magnet engineering. The following paragraphs discuss each of these technologies relative to the base case parameterization to determine the relative potential of each.

$H i g h-T_{c}$

At the time of this research (January 1992) high- $T_{c}$ superconductors were not available; progress has been rapid and the potential for a usable material within 5 years is quite real. Increased operating temperature via high- $\mathrm{T}_{\mathrm{e}}$ superconductors affects the optimization of SMES systems through a number of mechanisms:

- $\mathrm{LN}_{2}$ is significantly less expensive than LHe, 
- Cryogenic costs $\sim 1 / \mathrm{T}_{\text {op }}$,

- Increased $I_{\text {pack }}$ and number of coils due to reduced current lead losses, and

- Increased system reliability also expected (not quantified).

In this section, $\mathrm{T}_{\mathrm{op}}=30 \mathrm{~K}, 77 \mathrm{~K}$ are compared with the $4.2 \mathrm{~K}$ base case.

Figure 12 compares the base case $(4.2 \mathrm{~K}, 75 \mathrm{kA})$ with five variations: $4.2 \mathrm{~K}, 30 \mathrm{~K}, 77$ $\mathrm{K}, 75 \mathrm{kA}$, and $125 \mathrm{kA}$. At fixed $\mathrm{I}_{\text {pack }}=75 \mathrm{kA}$, the cost savings is significant when the temperature is increased to $77 \mathrm{~K}$ (about 35 percent). As shown, however, further cost reduction is obtained at $77 \mathrm{~K}$ by increasing $I_{\text {pack }}$ to $125 \mathrm{kA}$ (about 11 percent). This is in sharp contrast to Figure 11 , where increasing from $75 \mathrm{kA}$ to $125 \mathrm{kA}$ resulted in a cost increase of about 15 percent. Thus, to fully take advantage of increased $\mathrm{T}_{\mathrm{op}}$, larger conductors are required. Recall from Chapter 3 that a large $I_{\text {pack }}$ reduces the amount of stabilizer necessary for quench protection. Large $\mathrm{I}_{\text {pack }}$ is also important for obtaining rapid charge/discharge of the magnet.

$$
V=L \frac{d l}{d t}
$$

and recall Equation 13

$$
L_{\text {coll }}=\frac{2 E_{\text {stored }}}{I_{\text {pack }}^{2}}
$$

Thus, for constant $\mathrm{V}, \mathrm{E}_{\text {stored }}$,

$$
\frac{d l}{d t} \propto 1_{\text {pack }}^{2}
$$

This analysis indicates that increased $T_{\text {op }}$ leads to increased $I_{\text {pack }}$ and thus significant improvement in the SMES system. A further advantage of increased $\mathrm{T}_{\mathrm{op}}$ is a shift towards a larger number of coils in the toroidal array. This is illustrated in Figures 13 through 15 , which show the cost vs, number of coils for $\mathrm{T}_{\text {op }}=4.2 \mathrm{~K}, 30 \mathrm{~K}$, and $77 \mathrm{~K}$. As the number of coils increases, the volume of materials decreases.

Each coil, however, requires current leads, so at $4.2 \mathrm{~K}$, the cost increases with the number of coils because the cryogenic costs are a large percentage of the total cost (e.g., 43 percent with 16 coils at $12 \mathrm{~T}, 52$ percent with 24 coils at $12 \mathrm{~T}$ ). At higher $\mathrm{T}_{\text {op }}$, the relative cost of increasing the number of coils decreases when the temperature is increased from $4.2 \mathrm{~K}$ to $77 \mathrm{~K}$. The cost penalty of 24 coils relative to 16 coils is reduced 


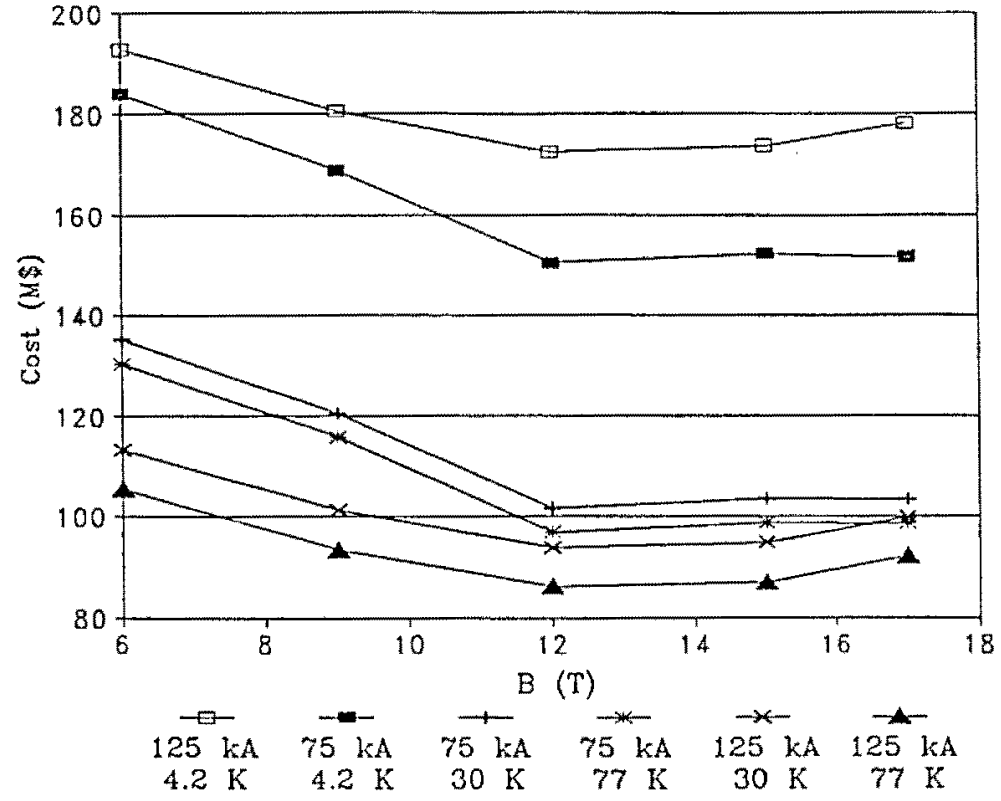

Figure 12. Cost vs. current and temperature.

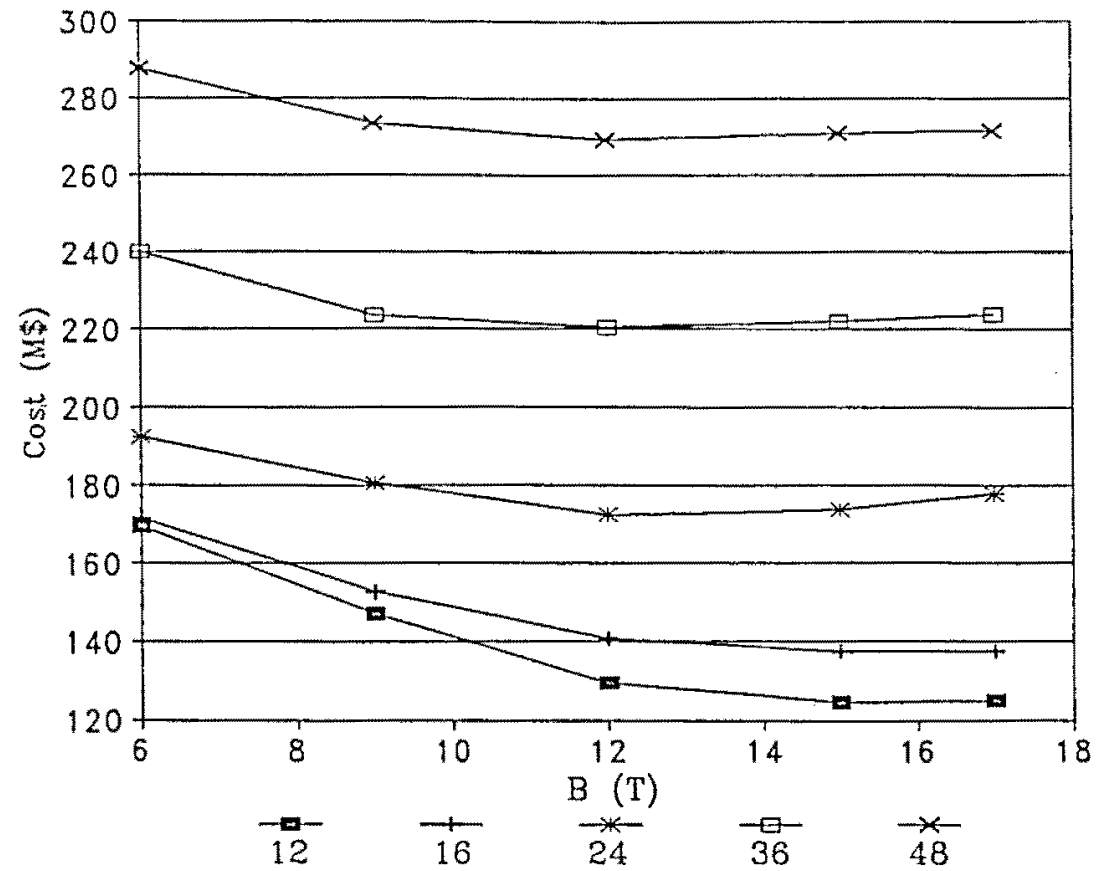

Figure 13. Cost vs. number of coils in the toroidal array at $4.2 \mathrm{~K}$. 


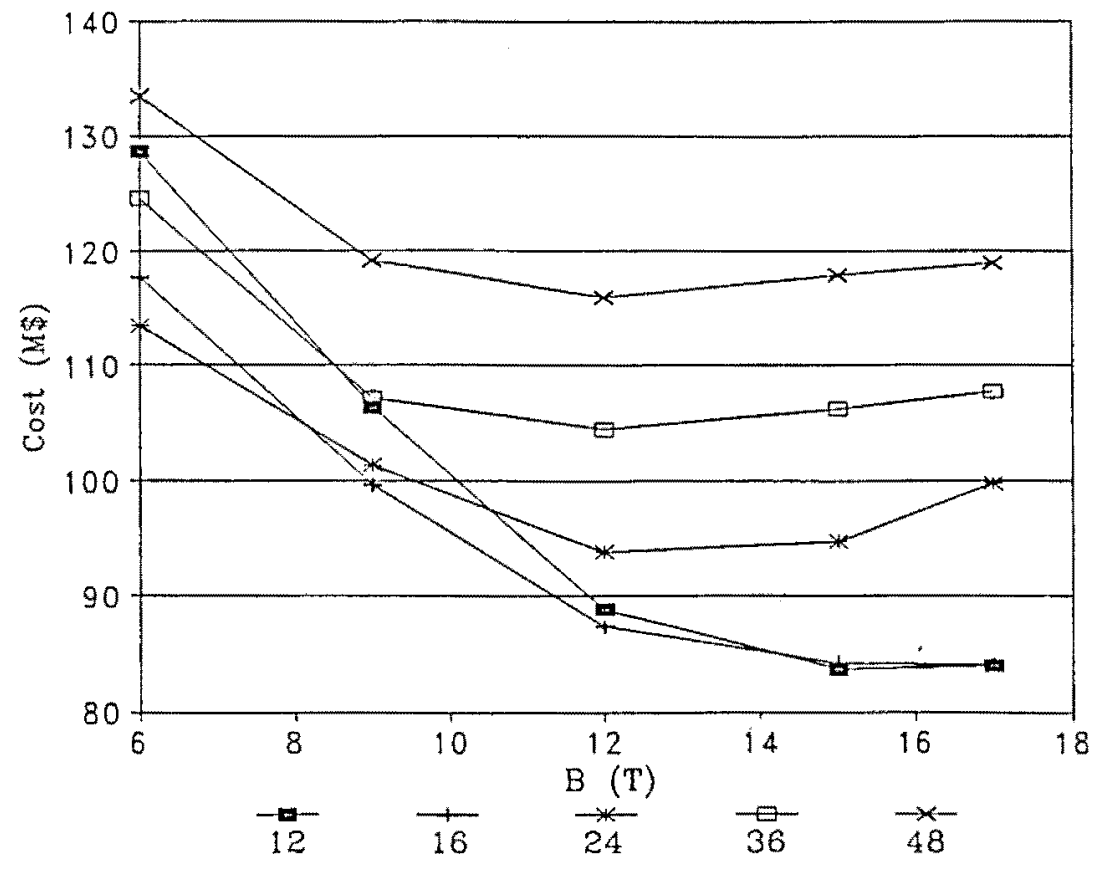

Figure 14. Cost vs. number of coils in the toroidal array at $30 \mathrm{~K}$.

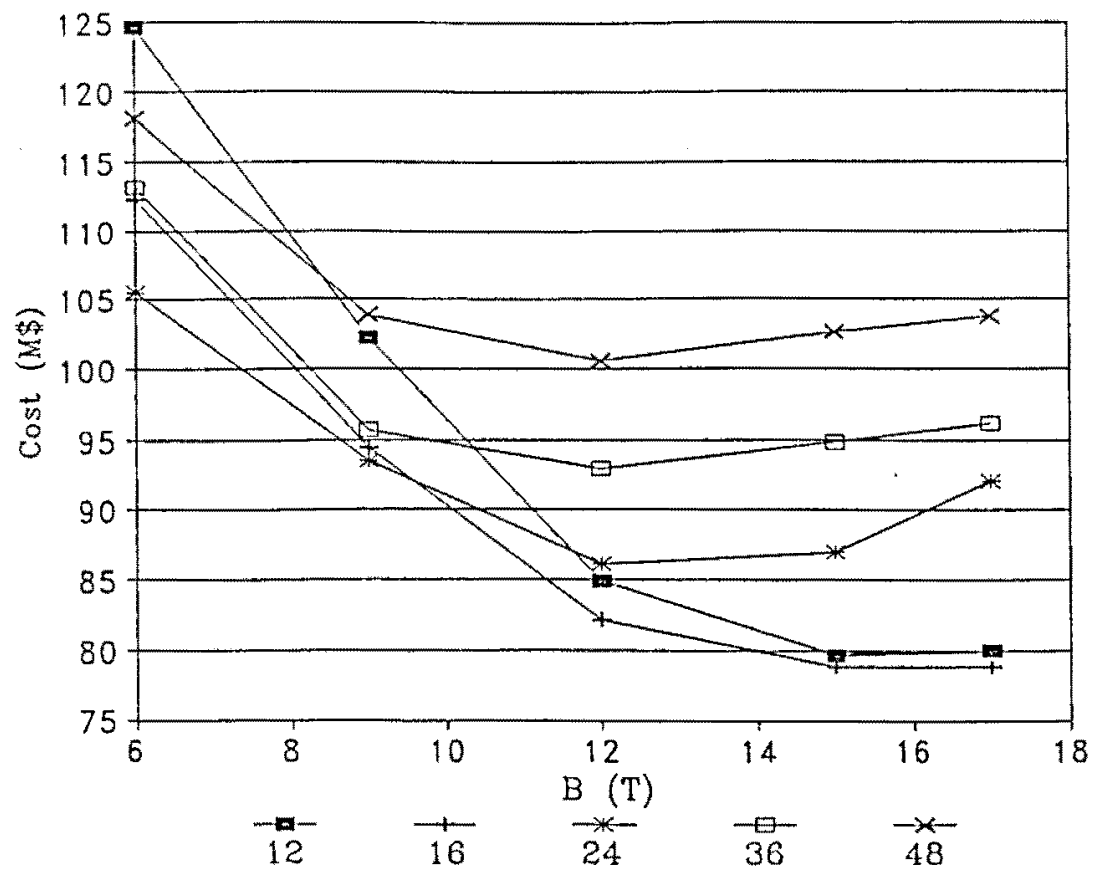

Figure 15. Cost vs. number of coils in the toroidal array at $77 \mathrm{~K}$. 
from 18.5 percent to 4.6 percent. Increasing the number of coils has the additional benefit of reducing the size of each individual coil so the manufacturing is simplified and the cost of replacing a failed coil is reduced greatly.

It is important to note that most of the savings is accrued by $30 \mathrm{~K}$; the cost reduction from $4.2 \mathrm{~K}$ to $30 \mathrm{~K}$ is significantly greater than from $30 \mathrm{~K}$ to $77 \mathrm{~K}$. This is a result of the $1 / \mathrm{T}_{\text {op }}$ scaling for the cryogenics. This has very important implications for the research and development of high- $\mathrm{T}_{\mathrm{c}}$ superconductors.

\section{Increased $J_{c}(B)$ at Fixed $T_{o p}$}

Along with developing high- $T_{c}$ superconductors, higher values of $J_{c}$ will also help decrease costs. As is seen in Figure 10, two variations of improved current densities were considered. Comparison at $4.2 \mathrm{~K}$ of the two variations of $J_{c}$ with the base case current density are shown in Figure 16. If $\mathrm{J}_{\mathrm{c}}$ can be raised to $2000 \mathrm{~A} / \mathrm{mm}^{2}$ at fields above $7 \mathrm{~T}$, the cost of a $15 \mathrm{~T}$ system decreases by $\$ 4.2$ million (2.8 percent). Similarly, if $J_{\mathrm{c}}$ values above $4000 \mathrm{~A} / \mathrm{mm}^{2}$ are obtainable, the cost is decreased by $\$ 5.7$ million (3.7 percent).

\section{High Strength $(\sigma)$ Structure}

The advantages of operating at higher allowed stress by using high strength materials were evaluated. The advantages include reduced volume of structural material and

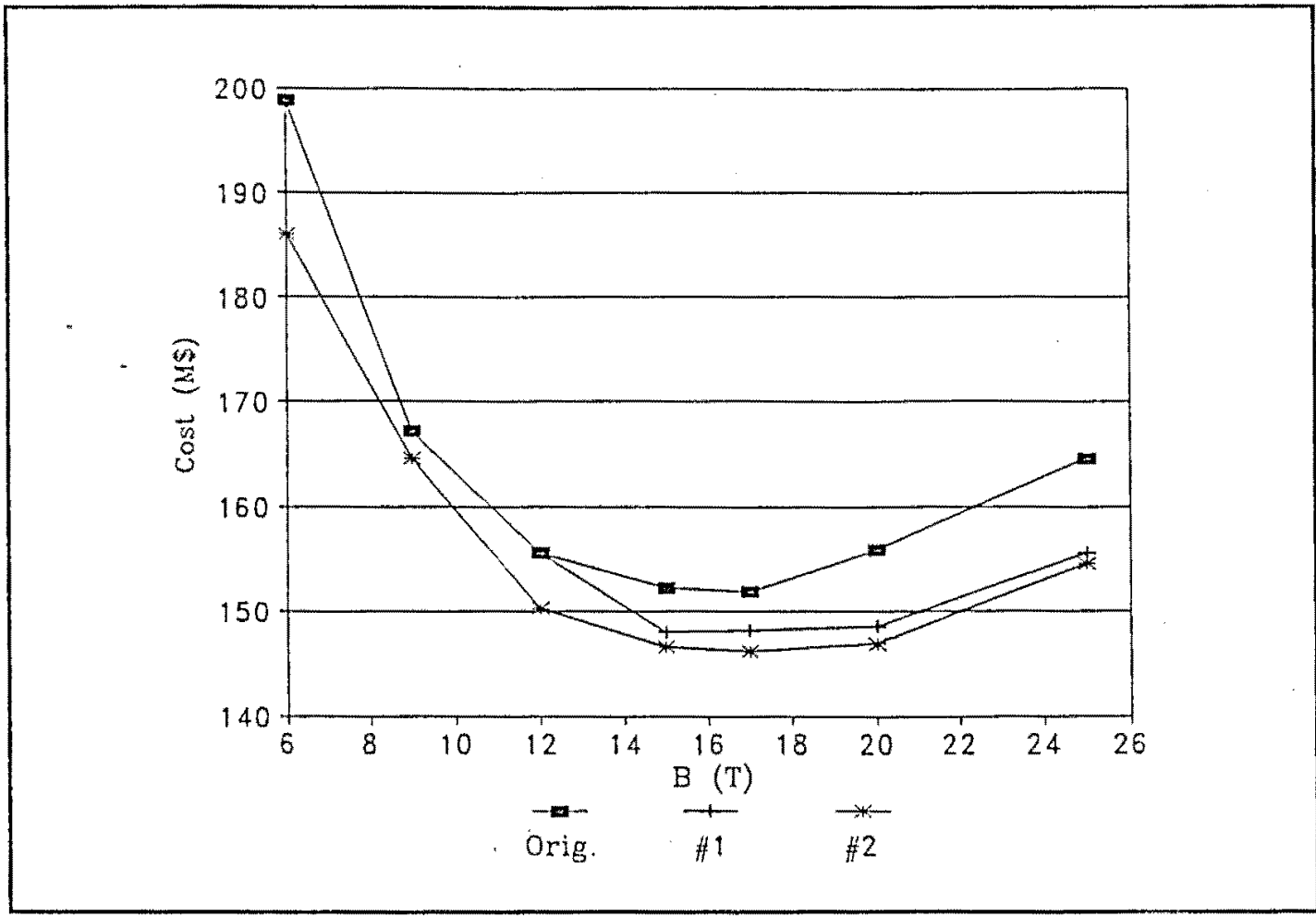

Figure 16. Cost vs. variations in current density. 
the option of operating at a higher magnetic field. By using carbon fibers, it is not unreasonable to envision a composite material capable of a Tresca equivalent allowed stress of $\sigma$ approximately $1.2 \mathrm{GPa}$ and a tensile Young's modulus of $300 \mathrm{GPa}$ in the fiber direction.

The effect of such a material is shown in Figure 17 at $4.2 \mathrm{~K}, 75 \mathrm{kA}$. Assuming identical unit costs for a carbon fiber composite as for Incoloy $908(\$ 60 / \mathrm{kg})$, the total cost of the system is reduced by $\$ 6.7$ million (about 4.4 percent). The optimum magnetic field may be reduced slightly.

\section{Performance Limit Via Advanced Materials}

After determining the optimum value for the current at $77 \mathrm{~K}(125 \mathrm{kA})$, the minimum cost was determined using the highest $J_{c}$ and allowed stress. This was analyzed for 16 and 24 coils. Figure 18 shows the results of these two cases. The minimum cost of $\$ 68.8$ million occurs when 16 coils are used at $17 \mathrm{~T}$. The minimum cost becomes $\$ 72.8$ million at $15 \mathrm{~T}$ if 24 coils are used. Thus, 16-coil SMES systems are more cost effective than 24-coil systems over a broad range of parameters; however, there will be less stray magnetic field and replacement of coils would cost less if 24 coils are used. When compared to the base case cost of $\$ 150.3$ million, the total cost is reduced by 45.8 percent by developing and using high- $\mathrm{J}_{\mathfrak{c}}$, high- $\mathrm{T}_{\text {op }}$ conductors and composite structures.

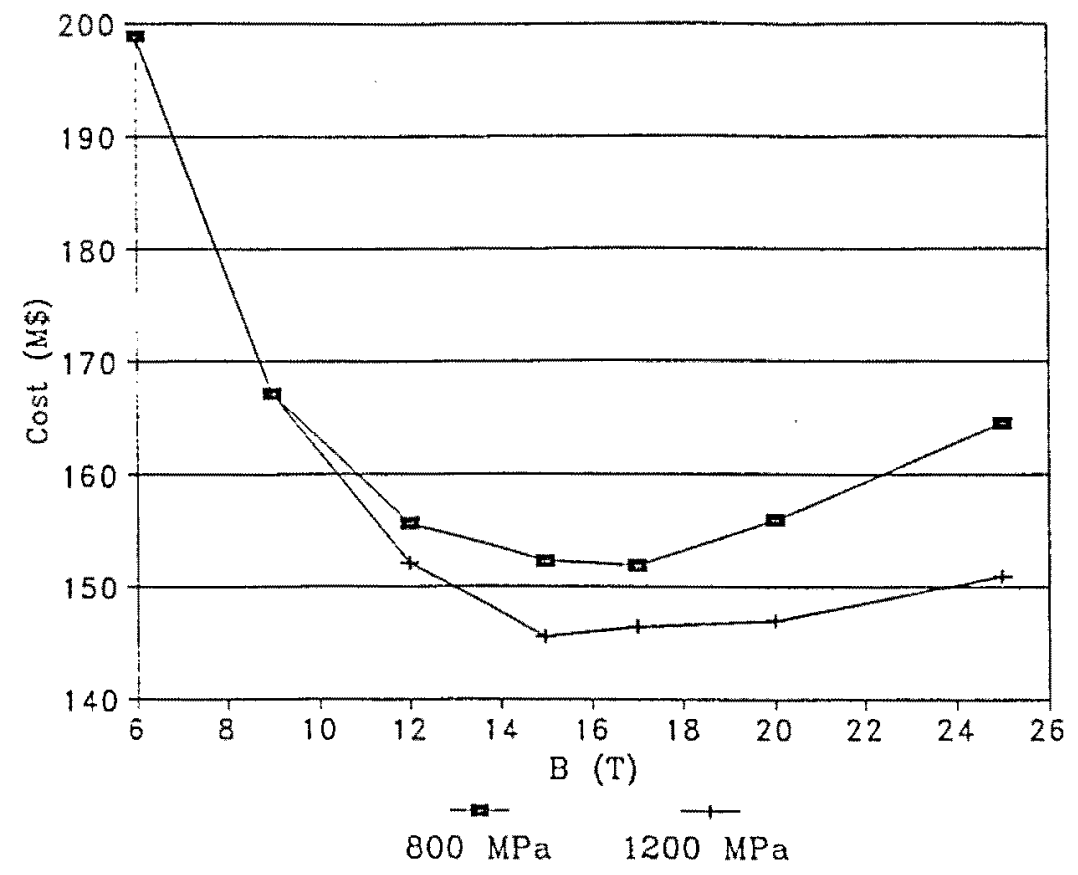

Figure 17. Effect of cost using high stress materials. 


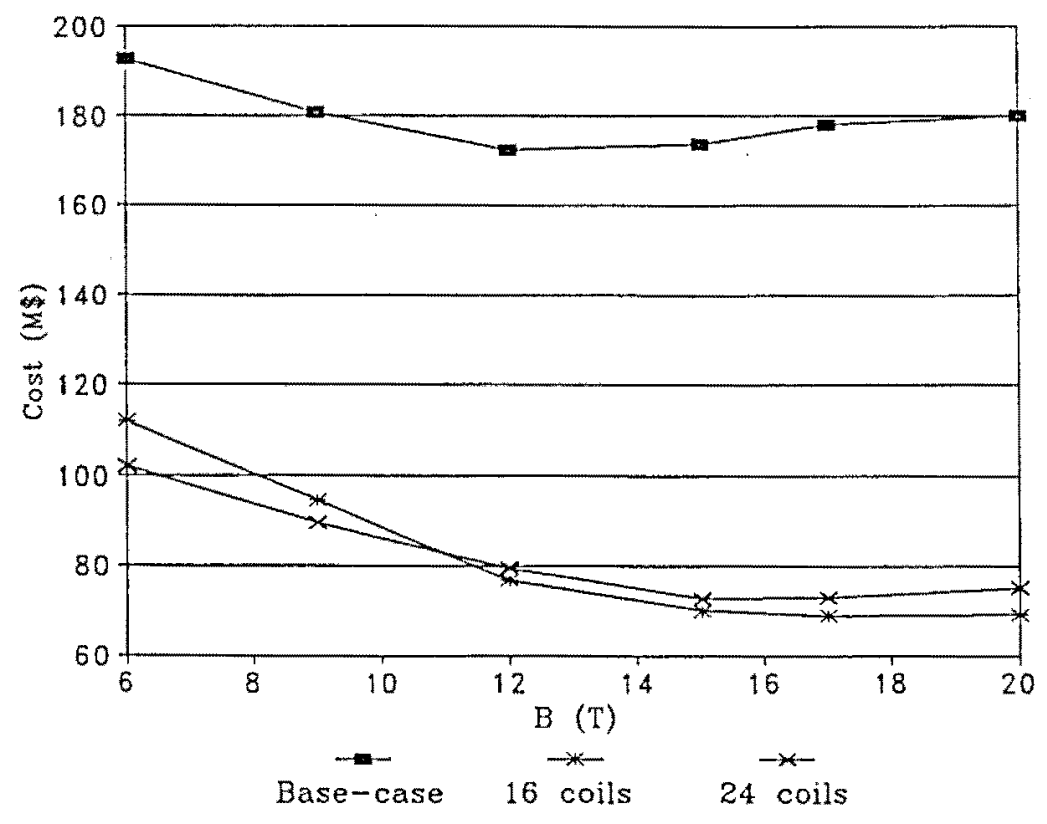

Figure 18. Minimum cost using advanced materials.

\section{Magnet Engineering}

Other factors that will affect superconducting magnets include increased reliability of the systems and coil designs. In January 1992, options such as force-reduced magnet designs were being researched. If successful, these coils would greatly reduce the amount of structural material required in the system.

The amount of structural material will be limited by the virial theorem that relates the stored energy to the integral of the trace of the stress tensor over the volume of the magnet. For a bounded, nonferromagnetic system, in equilibrium under Lorentz forces, this theorem states:

$$
\int \operatorname{Tr}(\underline{t}) d v=\int_{\text {space }} \frac{B^{2}}{2 \mu_{0}} d v \equiv E_{s t o r e d}
$$

where $\operatorname{Tr}(\underline{\underline{t}})$ is the trace of the stress tensor $\underline{\underline{t}}$ (Moon 1982). For structures with stresses in tension and compression, $\mathrm{S}_{\mathrm{T}}$ and $\mathrm{S}_{\mathrm{C}}$ respectively, Equation 54 becomes:

$$
S_{T} V_{T}-S_{C} V_{C}=E-M g z_{c}
$$


where $V_{T}$ and $V_{C}$ are the volumes under tension and compression, respectively, and $z_{c}$ is the height of the center of mass (Moon 1982). A more common form of this equation is when $\mathrm{ST}=\mathrm{SC} \equiv \mathrm{S}_{0}$ and the gravitational term is not considered (for conventional structural materials, the gravitational term is less than 1 percent of the stress term when $z_{c}$ is about $10 \mathrm{~m}$ ). This reduces Equation 54 to:

$$
M=(\rho E) /\left[S_{0}(1-2 \beta)\right]
$$

where $\rho$ is the average density and $\beta$ is the ratio of compressive volume to the total volume. This can be reduced further when a pure-tension toroidal design is used (i.e., $\mathrm{V}_{\mathrm{C}}=0$, hence, $\beta=0$ ). The relationship between energy and mass for toroidal field magnets for fusion can be seen in Figure 19 (Moon 1982). Clearly, existing magnets are not operating near the virial theorem limit. In the case of the magnet in this study, using $\mathrm{E}_{\text {stored }}=36 \mathrm{GJ}, \rho=7500 \mathrm{~kg} / \mathrm{m}^{3}$, and $\mathrm{S}_{0}=800 \mathrm{MPa}$, the minimum amount of structural mass required by the virial theorem is $3.38 \times 10^{5} \mathrm{~kg}$. The amount of structural material for the base case at $12 \mathrm{~T}$ is $7.52 \times 10^{5} \mathrm{~kg}$. So, if the virial limit is obtained, 45 percent of the structural material could be eliminated. At $\$ 60 / \mathrm{kg}$, this would account for a savings of almost $\$ 25$ million. Although it is unlikely that the virial theorem limit will be reached, this illustrates the potential impact of structurally optimized configurations.

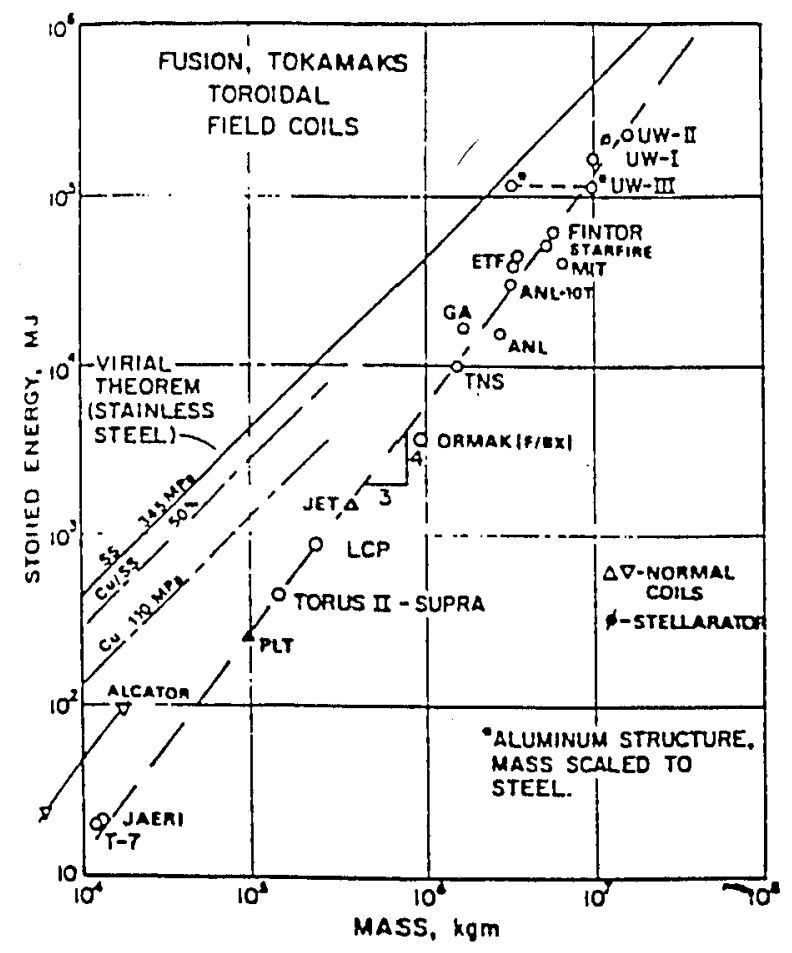

Figure 19. $E_{\text {stored }} v s$. structural mass for toroidal field magnets for fusion. 


\section{Summary and Conclusions}

\section{Summary}

As of January 1992, the storage of off-peak energy is receiving more attention due to the high cost of generating off-peak energy compared to peak energy and an unpredictable growth in peak demand. Superconducting magnetic energy storage (SMES) is one possible way to accomplish this.

Three other forms of energy storage are pumped-hydroelectric storage, battery storage, and compressed-air energy storage (CAES). Pumped hydroelectric power cannot always be used because it requires a large area to hold both the upper and lower reservoirs, and many of the ideal sites are already being used. The problem with battery storage is that the batteries only have a 15-year lifetime and they need to be filled with fresh water periodically. The main problem with CAES systems is the relatively high cost of $\$ 425 / \mathrm{kW}$.

SMES plants store off-peak electricity by converting ac power to dc and feeding it into a solenoid- or toroid-shaped magnet of superconducting wire. The main advantage of SMES over the other three forms of energy storage is its high efficiency (93.6 percent for a 5000MWh system, 91.6 percent for a $100 \mathrm{MWh}$ system, and 80 percent for a 10 MWh system). A large system, such as a $5000 \mathrm{MWh}$, would require a coil $1000 \mathrm{~m}$ in diameter; however, for a smaller system, such as $10 \mathrm{MWh}$, the coil may be as small as 3 to $4 \mathrm{~m}$ in diameter.

The two coil configurations typically considered for SMES systems are solenoids and toroids. Although solenoids are more commonly used, the toroid is preferable for this study. This is primarily the result of the smaller stray magnetic field in toroids, allowing the magnet to be located near a populated area. Also, factors such as fabrication, repair, and maintenance make the toroid more favorable.

Many issues need to be considered when designing a superconducting magnet. These include stability, quench protection, ac losses, and electromagnetic forces. Due to the positive feedback that is created when a magnetic field penetrates the superconductor or a small heat pulse enters the superconductor, stability needs to be maintained. The most common method for obtaining stability is using twisted filamentary composites. 
Quenching happens when any part of a superconducting magnet changes from the superconductive state to the normal state and stability cannot be maintained. The use of an external resistor is the simplest method of quench protection. AC losses occur from the changing of the magnetic field in a superconductor which creates an e.m.f. that raises the current density above the critical current density $\left(\mathrm{J}_{\mathrm{c}}\right)$ and into the resistive region. The stresses occurring due to the Lorentz forces depend on the type of coil used. For solenoids, the strongest magnetic field is in the axial direction on the inside of the coil. This produces an outward radial force and causes a circumferential hoop stress in the winding. For toroids, the magnetic field within the bore varies inversely with the major radius, and the coils are subject to strong bending forces.

The choice of materials considered includes both commercially available and developmental materials. At the present, the only commercially available superconductors are $\mathrm{NbTi}$ and $\mathrm{N}_{\mathrm{b}} \mathrm{S}_{\mathrm{n}}$ and its ternary compounds. Developmental superconductors include $\mathrm{Nb}_{3} \mathrm{Al}, \mathrm{V}_{2}(\mathrm{Hf}, \mathrm{Zr})$, and high- $\mathrm{T}_{\mathrm{c}}$ superconductors. The most commonly used stabilizers are high purity copper and aluminum. Composite materials with a copper or Al matrix may be higher strength options. Structural metals include cryogenic steels (SS316, JBK-75, Incoloy 908, Fe-Mn, and Fe-Cr alloys), maraging steels, and titanium alloys. Composites are another structural option. Generally, an aluminum or epoxy matrix is used; however, fibers such as polymers, boron, silicon carbide, and carbon can have a high longitudinal tensile strength and longitudinal modulus.

\section{Conclusions}

The first step in the analysis was to determine the lowest cost using commercially available materials. Once the base case materials and parameters were chosen, it was shown in Figure 11 that the minimum cost is $\$ 150$ million. It was then determined that the use of high $-T_{c}$ superconductors would allow higher values of $I_{\text {pack }}$. At both $30 \mathrm{~K}$ and $77 \mathrm{~K}, \mathrm{I}_{\text {pack }}$ was increased to $125 \mathrm{kA}$. The use of high- $\mathrm{T}_{\mathrm{c}}$ superconductors also decreased the difference between the cost of using 24 coils compared to 16 coils; however, the total cost using 24 coils never became less than the total cost using 16 coils. The effects of increasing $J_{c}(B)$ at fixed $T_{\text {op }}$ were also considered. This resulted in decreasing the total cost by 3.7 percent. High strength structural materials were the final area considered. Assuming the unit cost of the high strength materials can equal that of Incoloy 908 , the total cost could be reduced by 4.4 percent. When all advanced materials are employed, the total cost could be reduced by as much as 45.8 percent from the base case. Further, substantial cost reductions may be obtainable with structurally optimized winding approaches. 
Due to the present high cost of overcoming these various technological hurdles associated with constructing SMES systems, SMES does not appear to be a technology that is ready for use by most Army installations. As technological advances are made in superconducting materials, the cost of SMES will be reduced. Also, future wide-spread use of SMES would contribute to reduced design and materials costs compared to the present systems, which require individual design and construction. 


\section{References}

Allen, S.R., R.J. Farris, and E.L. Thomas, "High Modulus/High Strength poly-(p-phenylene benzobisthiazole) Fibres, Part 2," Journal of Material Science, No. 20 (1985), p 4583.

Anderson, C.H., and R. Warren. "Silicon Carbide Fibres and Their Potential for Use in Composite Materials. Part 1," Composites, vol 15, No. 1 (1984).

Avco Specialty Materials, Boron Composite Materials: AVCO Boron Characteristics for Strength and Stiffness at Minimum Weight, product information on available materials from Avco Specialty Materials TEXTRON (1988a).

Avco Specialty Materials, Low Cost Silicon Carbide Filaments for Metal Matrix Applications, product information on available materials from Avco Specialty Materials TEXTRON (1988b).

Bobrov, E.S., "Mechanical Characteristics of High Temperature Ceramic Superconductors," Applied Electromagnetics in Materials (1989), p 347.

Boenig, H.J., J.W. Dean, J.D. Rogers, R.I. Schermer, and J.F. Hauer, "Tests of the 30 MJ Superconducting Magnetic Energy Storage Unit," Journal de Physique, vol 45, No. 1 (January 1984), pp 575-580.

Boom, R.W., B.C. Haimson, G.E. McIntosh, H.A. Peterson, and W.C. Young, "Superconductive Energy Storage for Large Systems," IEEE Transactions on Magnetics, vol 11, No. 2 (March 1975), pp 475-481.

Boutacoff, D., "Emerging Strategies," EPRI Journal (July/August 1989), pp .4-13.

Broom, R.F., and E.H. Rhoderic, "Thermal Propagation of a Normal Region in a Thin Superconducting Film and its Application to a New Type of Bistable Element," British Journal of Applied Physics, vol 11 (July 1960), pp 292-296.

Buck, M.E., "High Strength and Modulus Filaments of Boron and Silicon Carbide," Materials Engineering and Design, VIII, No. 5 (1987), p 272.

Corn, D.L., "Cryogenic Properties of 18Ni-9Co-5 Mo and 18-Ni-7Co-5Mo Maraging Steel Sheet," Advances in Cryogenic Engineering, vol 12 (1966), p 532.

Dupont Kevlar "Kevlar 149: Properties and Characteristics of Yarn and Composites," product information on available materials from DuPont Kevlar (undated).

DuPont, Ultra High Modulus Carbon Fiber, DuPont Fiber G, Technical Specifications for E-130 (DuPont Kevlar, 1989). 
Ekin, J.W., "Strain Effects in Superconducting Compounds," Advances in Cryogenic Engineering, vol 30 (1984), p 823 .

File, J., R.G. Mills, and G.V. Sheffield, "Large Superconducting Magnet Designs for Fusion Reactors," IEEE Transactions on Nuclear Science, NS18, No. 4 (August 1971), pp 277-282.

Foner, S., "68.4 T Long Pulse Magnet: Test of High Strength Microcomposite Cu/Nb Conductor," Applied Physics Letters, vol 49, No. 15 (October 1986).

Gray, W., W. Stoddart, and J. Akin, "A Deviation of Bending Free Toroidal Shell Shapes for Tokamak Fusion Reactors," Transactions of the ASME Journal of Applied Mechanics, vol 46 (March 1979), pp $20-124$.

Green, M.A. Generation of the $J_{o} H_{c 2} T_{c}$ Surface for Commercial Superconductor Using Reduced-State Parameters, Technical Report (TR) LBL-24875 UC-423 (Lawrence Berkeley Laboratory, April 1988).

Hamada, T., T. Nishida, Y. Sajiki, M. Matsumoto, and M. Endo, "Structures and Physical Properties of Carbon Fibers from Coal Tar Mesophase Pitch," Journal of Materials Research, vol 2, No. 6 (November/December 1987), p 850.

Hassenzahl, W., "Superconducting Magnetic Energy Storage," IEEE Transactions on Magnetics, vol 25, No. 2 (March 1989), pp 750-758.

Herring, J.S., "Parametric Design Studies of Toroidal Magnet Energy Storage Units," 25th Intersociety Energy Conversion Engineering Conference (Idaho National Engineering Laboratory, August 1990).

Herring, J.S., "Safety and Stability in Superconducting Magnets," paper presented at the Winter Annual Meeting of the ASME, San Francisco, December 10-15, 1989, published in AES, Vol 9, pp 13-18.

Hoffman, E., J. Alcorn, W. Chen, Y-H. Hsu, J. Purcell, and R. Schermer, "Design of the BPA Superconducting 30 MJ Energy Storage Coil," IEEE Transactions on Magnetics, vol 17, No. 1 (January 1981), pp 521-524.

Kuroda, K., K. Inoue, H. Wada, and K. Tachikawa, "Superconducting Properties of V2 (Hf, Zr) Laves - Phase Multifilamentary Wires," IEEE Transactions on Magnetics, vol 19, No. 3 (May 1983).

Ky, Hoang Gia, "Development of NbTi Based Cables for LHC Dipoles," IEEE Transactions on Magnetics, vol 27, No. 2 (March 1991), pp 1822-1824.

Lontai, L.M., and P.G. Marston, Proceedings of the 1st International Conference on Magnet Technology, vol 723 (Stanford University Press, 1965).

Loyd, R.J., T.E. Walsh, and E.R. Kimmy, "Key Design Selection for the 20.4 MWh SMES/ETM," IEEE Transactions on Magnetics, vol 27, No. 2 (March 1991), pp 1712-1715. 
Martin, J., R.G. Ballinger, M.M. Morra, M.O. Hoenig, and M.M. Steeves, "Tensile, Fatigue, and Fracture Toughness Properties of a New Low Coefficient of Expansion Cryogenic Structural Alloy, Incoloy 9XA," Advances in Cryogenic Engineering, vol 34 (1988).

Masuda. M., Some Technological Topics Concerning the Efficiencies of Small or Medium Size SMES (Sagami Institute of Technology, Japan, September 1990).

Moon, F.C., "The Virial Therorem and Scaling Laws for Superconducting Magnet Systems," Journal of Applied Physics, vol 53, No. 12 (December 1982).

Moore T., "Pumped Hydro: Backbone of Utility Storage," EPRI Journal, vol 11, No. 1 (January/February 1986), pp 24-31.

Morgan, G.H., "Theoretical Behavior of Twisted Multicore Superconducting Wire in a Time-Varying Uniform Magnetic Field," Journal of Applied Physics, vol 41, No. 9 (August 1990), pp 3673-3679.

Morra, M.M., I.S. Hwang, R.G. Ballinger, M.M. Steeves, and M.O. Hoenig, "Effect of Cold Work and Heat Treatment on the $4 \mathrm{k}$ Tensile, Fatigue and Fracture Toughness Properties," Proceedings of Magnet Technology 11 (1989).

Morris, J.W., Jr., and E.N.C. Dalder, "Cryogenic Structural Materials for Superconducting Magnets," Journal of Metals (October 1985), p 24.

Morris, V.L., Advanced Composite Structures for Superconducting Supercollider (Structural Properties Industries, Inc, 1988 ).

Nagai, K., T. Yuri, O. Umezawa, and K. Ishikawa, "The Cryogenic Mechanical Properties of Ti and its Alloys," Cryogenic Materials '88, Volume 2: Structural Materials (1988 International Cryogenic Materials Conference, 1988), p 727.

Nakajima, H., K. Yoshida, M. Oshikiri, Y. Takahashi, K. Koizuma, S. Shimamoto, M. Shimada, S. Tone, S. Sakamoto, K. Suemune, and K. Nohara, "Tensile Properties of New Cryogenic Steels as Conduit Materials of Forced Flow Superconductors at $4 \mathrm{~K}$," Advances in Cryogenic Engineering, vol 34 (1988), p 173.

Neef, W.S., Structural Material Properties Relevant to Superconducting Magnet Applications, Memorandum (Lawrence Livermore National Laboratory, February 1988).

Ries, G., "AC-losses in Multifilamentary Superconductors at Technical Frequencies," IEEE Transactions on Magnetics, vol 13, No. 1 (January 1977), pp 524-526.

Rodriguez, G.D., W.C. Spindler, and D.S. Carr, Operating the World's Largest Lead-acid Battery Energy Storage System (undated).

Rodriguez, G.D., "Operating Experience With the Chino $10 \mathrm{MW} / 40 \mathrm{MWh}$ Battery Energy Storage Facility," 24th Intersociety Energy Conversion Engineering Conference (August 1989). 
Romanovskii, V.R., "Influence of Volume Fraction of Superconductor on the Stability of Superconducting Composites With Respect to Thermal Disturbances of Finite Extent," Cryogenics, vol 25 (June 1985).

Schwartz, J., Design and Stability of a High Field (> 20T) Toroidal Field Coil Using Advanced Superconducting and Structural Materials, $\mathrm{PhD}$ thesis (Massachusetts Institute of Technology, February 1990).

Shimizu, M., Y. Tanabe, T. Yoshioka, K. Takeda, T. Hamajima, N. Miki, Y. Nakayama, M. Udo, N. Takeda, H. Miyazaki, K. Kamemura, and M. Yamamoto, "Feasibility Study of a $10 \mathrm{GWh}$ Toroidal Superconductive Magnetic Energy Storage System. System Design," Journal de Physique, vol 45, No. 1 (January 1984a), pp 581-585.

Shimizu, M., T. Yoshioka, Y. Morita, Y. Tanabe, T. Hamajima, N. Fujiwara, N. Miki, M. Yamaguchi, T. Horiuchi, N. Takeda, H. Miyazaki, and K. Kamemura, "Feasibility Study of a 10 GWh Toroidal Superconductive Magnetic Energy Storage System. Conceptual Design of Coil System," Journal de Physique, vol 45, No. 1 (January 1984b), pp 587-590.

Suemune, K., T. Sakamoto, T. Ogawa, T. Okazaki, and S. Maehara, "Manufacture and Properties of Nitrogen-Containing $\mathrm{Cr}-\mathrm{Mn}$ and $\mathrm{Cr}-\mathrm{Ni}$ Austenitic Stainless Steels for Cryogenic Use," Advances in Cryogenic Engineering, vol 34 (1988), p 123.

Teledyne Vasco, product information on VascoMax C-200,C-250,C-300,C-350, 1982.

Timoshenko, S., Strength of Materials, II: Advanced Theory (Van Nostrand Reinhold, New York, NY 1941).

Togano, K., and K. Tachikawa, "Fabrication of $\mathrm{Nb}_{3} \mathrm{Al}$ Based Superconductors by Continuous Quenching Techniques," Advances in Cryogenic Engineering, vol 34 (1988).

Toray Industries, Inc., "Torayca Technical Reference Manual," product information on available materials from Toray Industries, Inc. (1988).

Watanabe, K., K. Noto, and Y. Muto, "Upper Critical Fields and Critical Current Densities in Bronze Processed Commercial Multifilamentary $\mathrm{Nb}_{3}$ Sn Wires," IEEE Transactions on Magnetics, vol 27, - No. 2 (March 1991), pp 1759-1762.

Wilson, M.N., Superconducting Magnets (Oxford University Press, 1983). 


\section{USACERL DISTRIBUTION}

Chief of Engineers

ATTN: CEHEC-IM-LH (2)

ATTN: CEHEC-IM-LP (2)

ATTN: CECC-R

ATTN: CERD-L

CECPW 22310-3862

ATTN: CECPW-E

Defense Tech Info Center 22304

ATTN: DTIC-O (2)

$12 / 95$ 

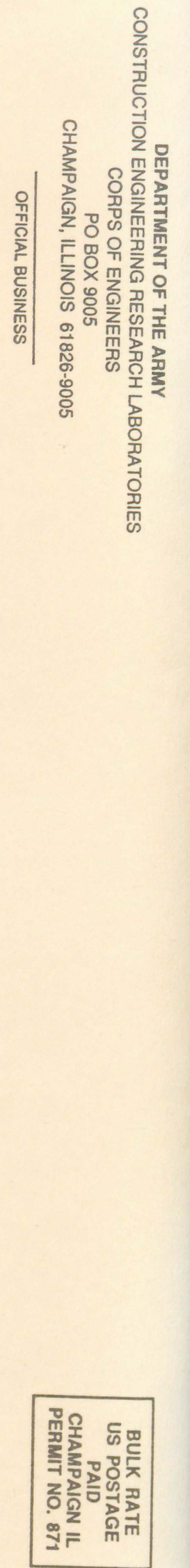